\title{
A survey of the European Union's artificial intelligence ecosystem
}
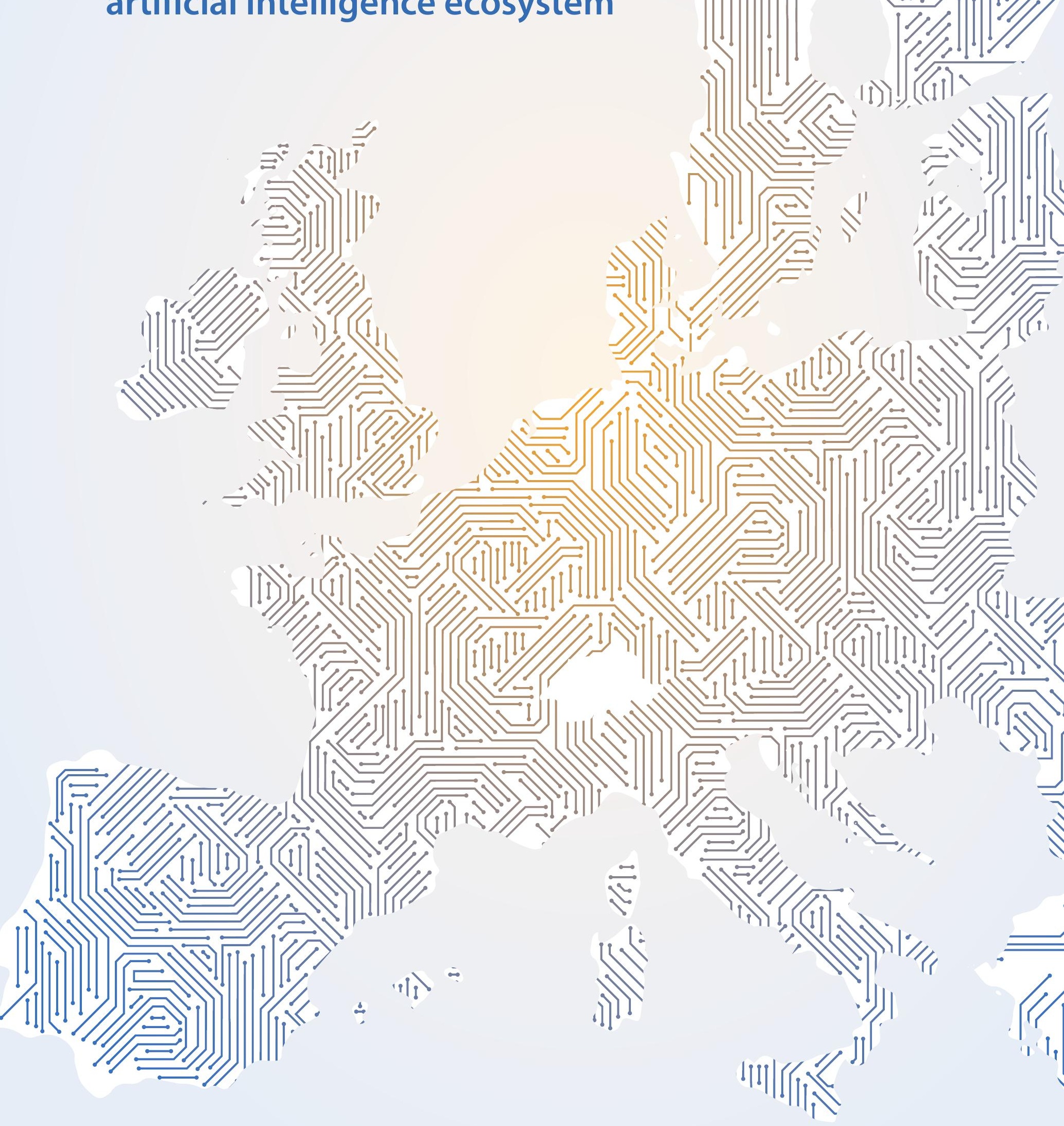


\section{Compiled by Charlotte Stix}

Research Associate, Leverhulme Centre for the Future of Intelligence, University of Cambridge Advisor, Element Al

This report is by no means final or comprehensive. It will act as a living document regularly undergoing updates to reflect the rapidly changing Al landscape within the European Union.

Thanks for edits and comments to Seán Ó hÉigeartaigh, Stephen Cave, Matthijs M. Maas, Jess Whittlestone, Emma Bates, Rune Nyrup and Haydn Belfield. 


\section{Contents:}

\section{Executive Summary}

\section{Introduction}

\section{Part One: The overarching plan}

\section{The European Union's Al strategy}

Digital Day Declaration, 'Declaration of Cooperation on Artificial Intelligence'

European Commission's 'Communication on Artificial Intelligence'

European Commission's 'Coordinated Plan on Artificial Intelligence'

High-Level Expert Group on Artificial Intelligence

European Artificial Intelligence Alliance

\section{The European Union's vision}

European Group on Ethics in Science and New Technologies' statement on 'Artificial Intelligence, Robotics and 'Autonomous Systems"

High-Level Expert Group on Artificial Intelligence's ‘Draft Ethics Guidelines for Trustworthy Artificial Intelligence'

European Economic and Social Committee's 'Opinion on Al, Artificial intelligence The consequences of artificial intelligence on the (digital) single market, production, consumption, employment and society'

General Data Protection Regulation and ePrivacy Regulation

DECODE

Algo Awareness

\section{Part Two: The ingredients}

\section{Funding and financial support}

VentureEU

European Fund for Strategic Investment

European Innovation Council

Horizon 2020 (2018-2020)

Digital Europe programme (2021-2027) 


\section{Talent creation}

New Skills Agenda

Digital Skills and Jobs Coalition

Putting the pieces back together

(i) Large-scale collaboration

\section{(i.a) Active collaboration: infrastructure}

Al4EU: Al-on-demand platform

Digital Innovation Hubs

\section{(i.b) Active collaboration: R\&D\&l and hardware}

\section{SPARC}

Electronic Components and Systems Joint Undertaking

European High-Performance Computing Joint Undertaking

(i.c) Proposals for collaboration: pan-European Al laboratories

A 'CERN for $\mathrm{Al}^{\prime}$

European Lab for Learning \& Intelligent Systems

Confederation of Laboratories for Artificial Intelligence Research in Europe

\section{(ii) Granular collaboration}

Joint European Disruptive Initiative

Paris Artificial Intelligence Research Institute

European Association for Artificial Intelligence

\section{Summary}

\section{Appendix}




\section{Acronyms:}

AAAl: $\quad$ Association for the Advancement of Artificial Intelligence

AENEAS: $\quad$ Association for European NanoElectronics ActivitieS

Al: $\quad$ Artificial Intelligence

Al HLEG : High-Level Expert Group on Artificial Intelligence

ARM: $\quad$ Acorn RISC Machine

ARTEMIS: $\quad$ Advanced Research \& Technology for EMbedded Intelligent Systems

CERN: $\quad$ Conseil Européen pour la Recherche Nucléaire (European Organization for Nuclear Research)

CIIRC: $\quad$ Czech Institute of Informatics, Robotics and Cybernetics

CLAIRE: $\quad$ Confederation of Laboratories for Artificial Intelligence Research in Europe

DARPA: $\quad$ American Defense Advanced Research Projects Agency

DIHs: Digital Innovation Hubs

ECAl: $\quad$ European Conference on Artificial Intelligence

ECSEL: $\quad$ Electronic Components and Systems Joint Undertaking

EESC: $\quad$ European Economic and Social Committee

EFSI: $\quad$ European Fund for Strategic Investment

EGE: $\quad$ European Group on Ethics in Science and New Technologies

EIB: $\quad$ European Investment Bank

EIF: $\quad$ European Investment Fund

ELLIS: $\quad$ European Lab for Learning \& Intelligent Systems

EPoSS: $\quad$ European Platform on Smart Systems Integration

EU: $\quad$ European Union
EurAl: $\quad$ European Association for Artificial Intelligence

GDPR: General Data Protection Regulation

HBP: $\quad$ Human Brain project

EuroHPC JU: High-Performance Computing Joint Undertaking

HQ: Headquarters

H2020: Horizon 2020

ICT: Information and Communications Technology

IEEE: The Institute of Electrical and Electronics Engineers

IJCAI: International Joint Conference on Artificial Intelligence

JEDI: Joint European Disruptive Initiative

MAR: $\quad$ SPARC's Multi-Annual Roadmap

MILA: $\quad$ Montreal Institute for Learning Algorithms

MOOC: $\quad$ Massive Open Online Course

MFF: Multiannual Financial Framework

NATO: North Atlantic Treaty Organization

PPP: $\quad$ Public-Private Partnership

PRAIRIE: Paris Artificial Intelligence Research Institute

R\&D: $\quad$ Research and Development

R\&D\&l: Research, Development and Innovation

SMEs: $\quad$ Small and Medium sized Enterprises

SPARC: $\quad$ Public-Private Partnership for robotics in Europe

SRA: $\quad$ SPARC's Strategic Research Agenda

STEM: Science, Technology, Engineering and Math

S\&T: $\quad$ Scientific and Technological

VC: Venture Capital

WG: $\quad$ Working Groups 


\section{Executive Summary}

Narratives in international media, and increasingly within governments, place great importance on nations achieving leadership in artificial intelligence (AI). The $\mathrm{EU}^{1,2}$ is rarely considered the leading player in these discussions. ${ }^{3}$ This report investigates this assumption and outlines existing building blocks that could form the basis for EU leadership in Al. The research is based primarily around EU legislation, policy and strategy documents, publicly available databases of ongoing projects, and funding decisions. In aggregating this information, the report aims to provide an introductory overview of the EU's Al ecosystem.

The report is structured into the following sections: (1) strategy and vision ${ }^{4,5}$ and (2.a) funding and financial support, (2.b) talent creation ${ }^{6,7}$ (2.c) collaboration. ${ }^{8}$ The primary conclusions around each of these are as follows:

(1) The EU, via the European Commission in their Communication on $\mathrm{Al}$, sets out a "European Initiative on Al" as well as a Coordinated Plan on Al from the EU Member States. ${ }^{9}$ This initiative is supported with a declaration signed by all 28 Member States, the Declaration of Cooperation on Al. The Coordinated Plan on Al outlines how EU Member States could coordinate their strategies, financial commitments and other resources to increase European competitiveness as a whole. Perhaps most notably, the EU's vision for $\mathrm{Al}$ is centered around 'ethical Al' in a way that could distinguish it from its American or Chinese counterparts. (2.a) Although it is too early to judge their impact, the EU is undertaking active steps to tackle funding bottlenecks. ${ }^{10}$ The European Commission will invest $€ 1.5$ bn $^{11}$ between 20182020 towards research and innovation in Al, a $70 \%$ increase from current investments, and expects to invest $€ 2.5 \mathrm{bn}^{12}$ during the Digital Europe Programme (2021-2027) alone. These numbers exclude funding from other sources such as the European Research Council and the European Fund for Strategic Investment. The EU is struggling to attract venture capitalists. They invested only $€ 6.5 \mathrm{bn}$ in the EU in 2016, in comparison to $€ 39.4 \mathrm{bn}$ in the US. ${ }^{13}$ Newlyestablished initiatives such as VentureEU aim to redress this imbalance.

(2.b) The EU has a number of initiatives dedicated to talent creation for the ICT and digital sector. However, there is mounting concern over brain drain and a loss of future-oriented entreprises, with researchers leaving the EU and a number of promising companies being acquired by international companies, such as Acorn RISC Machine (acquired by SoftBank), ${ }^{14}$ KUKA (Midea), ${ }^{15}$ and Magic Pony Technology (Twitter) ${ }^{16}$. Talent creation through education, re- and upskilling may put the EU on a solid foundation for future Al competitiveness, but brain drain remains a substantial concern. 
(2.c) The EU has several ongoing and upcoming initiatives between Member States and groups within those that are of collaborative nature. Large-scale infrastructural collaborations such as the Digital Innovation Hubs and the AI4EU pilots exist alongside prominent collaborations on resources, evidenced by the Joint Undertakings for electronic components as well as highperformance computing. Looking forward, the EU could build on a track record of major collaborative projects such as the Human Brain Project and CERN, which could provide a model for collaborative Al initiatives of similar scale.

This report does not judge whether these components will suffice for the EU to achieve or maintain Al leadership. Future work will be needed to assess the effectiveness of these initiatives and compare them to those of other nations. However, by providing an overview of the EU Al ecosystem this report hopes to open a broader discussion about what EU leadership in Al could look like and highlight many of the components that could provide its basis.
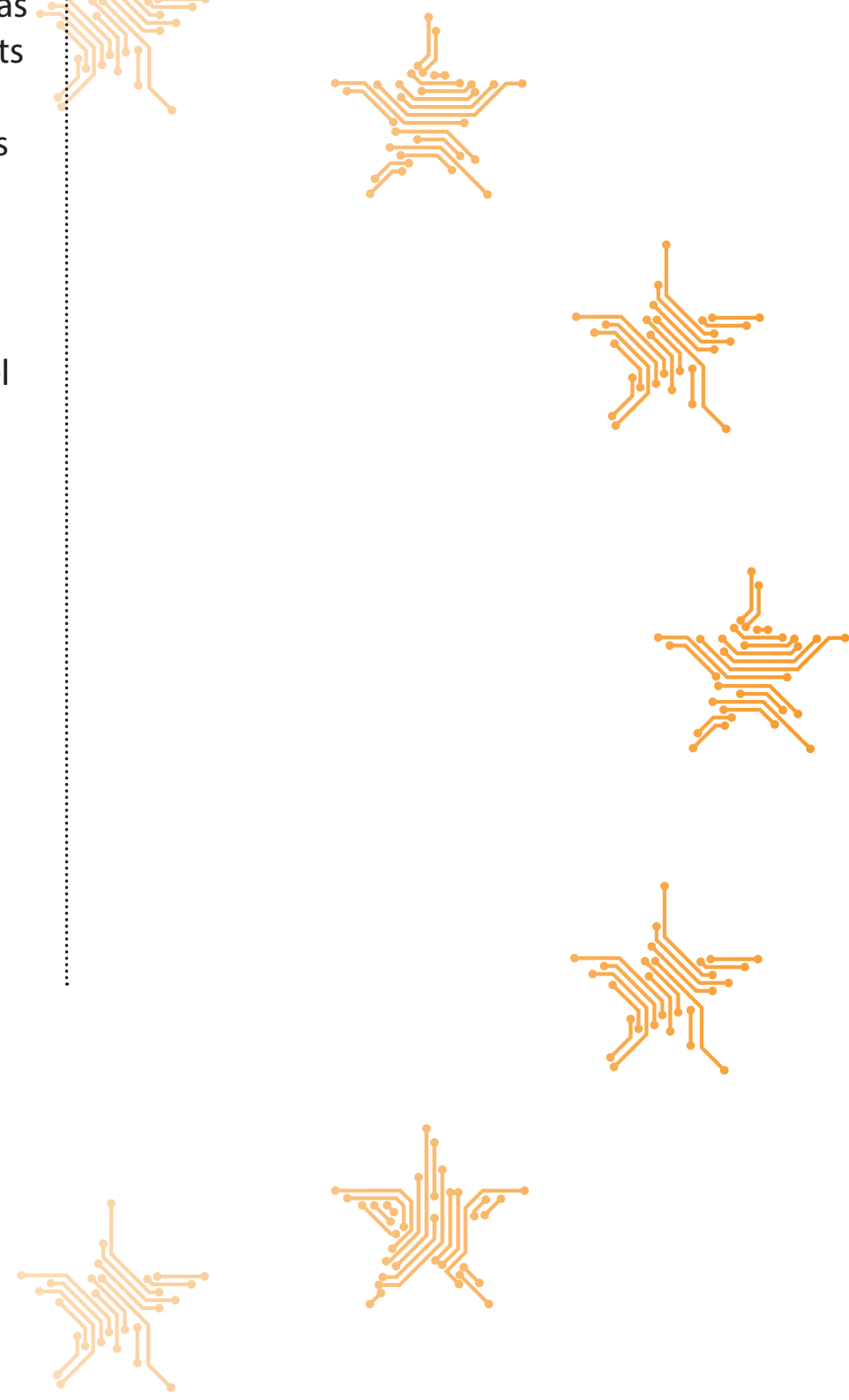


\section{Introduction}

Recent progress in Al has led a variety of countries to set up governmental advisory boards, propose Al strategies and establish new institutions that focus on the societal impact of this technology. Some countries and strategies feature more prominently in public fora than others. This has the potential to contribute to a misleading impression of the shape and state of the global Al ecosystem. In contrast to other global powers, the EU appears at times reluctant to trumpet achievements, initiatives or ambitions, be that in Al or other fields. As a result, awareness about the work undertaken by the EU is often lacking, which, in turn, contributes to the narrative that it is on the waiting bench when it comes to Al.

This report aims to rectify this impression by providing a deeper insight into the EU's AI ecosystem through an investigative tour of past, current and proposed Al-relevant activities. Several areas are examined in a closer manner: (1) strategy and vision, ${ }^{17,18}$ (2.a) funding and financial support, (2.b) talent creation, ${ }^{19,20}$ and (2.c) collaboration. ${ }^{21}$

Part 1 outlines the EU's strategy and vision with regard to Al. It is divided into two sections. Section (a) looks directly at the EU's AI strategy. Section (b) explores the accompanying vision.

Section (a) outlines the EU's Al strategy through the introduction of three key publications: the Digital Day Declaration 'Declaration of Cooperation on $\mathbf{A l}^{\prime}$, the European Commission's 'Communication on Artificial Intelligence' and the European Commission's 'Coordinated Plan on $\mathbf{A l}^{\prime}$. It then presents the two groups that help steer the European Commission in the implementation of several components of these strategy documents: the High-Level Expert Group on Artificial Intelligence and the European Artificial Intelligence Alliance. The first group is composed of 52 subject experts who act as an advisory group to the European Commission on ethics, investment and policymaking and work on outlining a long-term Al strategy. The second group is a multi-stakeholder forum open to all EU citizens to share their opinion, concerns and feedback on developing Al policy and strategy. Crystallising out of section (a) is the image of the EU as an actor that selfidentifies as a leader in 'ethical $\mathrm{Al}^{\prime 22}$

Section (b) explores this on the basis of recent reports, papers, regulations and EU-funded projects. It introduces three relevant documents, the European Group on Ethics in Science and New Technologies' statement on 'Artificial Intelligence, Robotics and 'Autonomous Systems”, the High-Level Expert Group's 'Draft Ethics Guidelines on $\mathbf{A l}^{\prime}$, and the European Economic and Social Committee's 'Opinion on Artificial Intelligence'. ${ }^{23}$ All three publications demonstrate the importance that actors within the EU place on human-centric and 'ethical Al'. This is followed by a brief examination of regulations that could contribute to 'ethical $\mathrm{Al}^{\prime}$, such as the General Data Protection Regulation and ePrivacy Regulation. Finally, two EU funded projects are discussed, concerning related issues such as data usage, ownership and algorithmic decision making from a non-regulatory perspective: DECODE and Algo Awareness. Part 1 concludes with a summary of the EU's Al strategy and vision. 
Part 2 then investigates the granular elements that will support the EU in the implementation of its strategy and vision. It is divided into three sections: (a) funding and financial support, (b) talent creation and (c) collaboration.

Section (a) explores funding and financial support. It looks at the newly proposed VentureEU fund and the European Fund for Strategic Investment. It then broadly covers other funding sources for research, development and innovation such as the Horizon 2020 framework programme for research and innovation (2018-2020), Horizon Europe (20212027) succeeding Horizon 2020, the European Innovation Council and the upcoming Digital Europe Programme.

Section (b) explores talent creation. The EU tackles talent creation through education, upskilling and reskilling, as evidenced by e.g the New Skills Agenda and the Digital Skills and Jobs Coalition. Various national strategies, such as Germany's Eckpunkte der Bundesregierung für eine Strategie Künstliche Intelligenz, ${ }^{24}$ Finland's Age of Artificial Intelligence ${ }^{25}$ and France's Donner un sens à l'intelligence artificielle ${ }^{26}$ propose more direct next steps to halt brain drain.

Section (c) investigates areas of collaboration and cooperation. It is divided into two subsections: (i) exploring initiatives at macrolevel (i.e. collaborations between Member States) and (ii) exploring initiatives at a more granular level. Subsection (i) highlights existing collaborative infrastructure: the AI4EU project (formerly Al-on-demand platform) and the Digital Innovation Hubs initiative. Both aim to increase access to Al, including to data, tools, and advice, for small and medium sized enterprises (SMEs). This is followed by the introduction of a number of other EU-wide collaborations that are likely to play an important role for the EU's Al leadership. In particular, it outlines SPARC, a Public-Private Partnership between the European Commission and the robotics community, the Electronic Components and Systems Joint Undertaking and the European HighPerformance Computing Joint Undertaking.
The latter two both focus on Al-relevant hardware. It ends with the introduction of three eminent proposals for a European Al laboratory: CERN for Al, the European Lab for Learning \& Intelligent Systems and the Confederation of Laboratories for Artificial Intelligence Research in Europe.

Subsection (ii) explores more granular collaborative actions and initiatives. The Joint European Disruptive Initiative is a FrancoGermanic initiative that aims to redress the EU's lack of funding for 'moonshot' projects. The Paris Artificial Intelligence Research Institute is a proposed initiative to develop a distributed Al research "institute of institutes" across Paris with links to global Al labs. The report then focuses on academic collaborations by introducing EurAl, the European Association for Al. In light of the identified initiatives, community movements and ongoing networks, Part 2 concludes with a summary of current opportunities as well as drawbacks.

The report ends with two main conclusions. The first is that the EU has a suitable and encouraging framework to become a leader in 'ethical Al'. This includes regulations, citizen engagement and the development of ethics guidelines. ${ }^{27}$ While leadership in 'ethical Al' is important, it must be incorporated within the broader goals of an EU Al strategy and the proposed implementation process of the European Commission's Coordinated Plan on $\mathrm{Al}^{28}$ This will likely require continued support for cutting-edge research capability in Al and for successful commercial applications of Al as well as the meaningful alignment of national Al strategies. The second conclusion is that the EU should pay diligent attention to the funding for start-ups and talent brain drain while the impact of newly established and proposed initiatives remains unclear.

The annex provides a brief overview of existing large-scale pan-European collaborations. These are not directly related to $\mathrm{Al}$, but provide a model for what the EU could aim for when it comes to large-scale Al research: CERN and the Human Brain project. 


\section{Part 1: The overarching plan}

Part 1 outlines the EU's overarching strategy and vision. It is divided into two sections: (a) looks at recent developments with regard to the EU's AI strategy, and presents the EU's intention to be a leader in 'ethical Al'. Section (b) supports the picture of the EU as a viable leader in 'ethical $\mathrm{Al}^{\prime}$ on the basis of recent reports, papers, regulations and relevant EU projects. Subsequently, part 2 places this general strategy within the broader ecosystem and explores areas of collaboration, funding and talent creation.

\section{Section (a): The European Union's Al strategy}

In 2018, the European Commission presented the Digital Day Declaration 'Declaration of Cooperation on $\mathrm{Al}^{\prime 29}$ now signed by all 28 Member States (plus Norway). In the Declaration, ${ }^{30}$ Member States agree to stay in close dialogue with the European Commission and to work together towards "a comprehensive and integrated European approach on Al and, where needed, review and modernise national policies to ensure that the opportunities arising from $\mathrm{Al}$ are seized and the emerging challenges addressed." ${ }^{31}$

The main goal of the Declaration is to build a framework for cooperation between Member States on areas ranging from Al's impact on the labour market, sustainability and trustworthiness to ethics and funding. Furthermore, the Declaration draws attention to pressing challenges in areas such as education and reskilling. Other points deal with, for example, the importance of cooperation when it comes to the expansion of and support for Al research centres, a salient point related to the discussions in Part 2. It also touches upon the mitigation of arising legal, ethical and socio-economic risks.

In fact, the Declaration demonstrates a clear concern for the ethical issues arising out of current and future Al-system's development and deployment. Following this concern, it commits its signatories to ensuring that 'humans remain at the centre of Al development', and to prevent the "harmful creation and use of Al applications".32,33

Despite its non-binding nature, the Declaration should be seen as a serious demonstration of intent on behalf of the Member States to collaborate on $\mathrm{Al}$ and to strengthen $\mathrm{EU}$ leadership. An intent taken up from the European Commission's 'Communication on $\mathrm{Al}^{\prime}$ and further sustained by the subsequent 'Coordinated Plan on $\mathrm{Al}^{\prime}$.

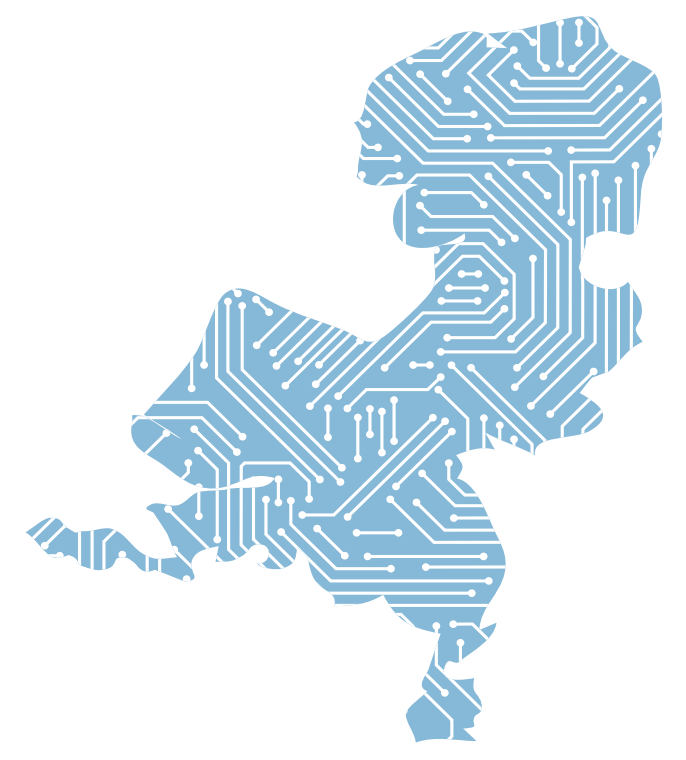




\section{Declaration of Cooperation on Al}

Published: 10th April 2018

Signatories: original signatories: Austria, Belgium, Bulgaria, Czechia, Denmark, Estonia, Finland, France, Germany, Hungary, Ireland, Italy, Latvia, Lithuania, Luxembourg, Malta, Netherlands, Poland, Portugal, Slovakia, Slovenia, Spain, Sweden, UK, Norway; the rest of the Member States have signed since; Member States commit to stay in close dialogue with the European Commission.

Aim: "The signatories of this declaration commit to a regular assessment of the achievements and progress made on the matters agreed above and on the adoption of the appropriate measures in order to adequately react to the emerging evolution of $\mathrm{Al}$ and the opportunities and challenges related thereto." ${ }^{34}$

One of the two core strategy documents of the European Commission is the 'Communication on $\mathrm{Al}^{\prime}, 35$ published in response to the European Council's call to put forward a European approach to Al. The Communication effectively lays the groundwork for the 'Coordinated Plan on $\mathrm{Al}^{\prime}$ and outlines the steps needed to achieve a more committed alignment of resources and goals between Member States. The whole, it appears, is expected to be greater than the sum of its parts. To that end, the Communication states that the EU "should have a coordinated approach to make the most of the opportunities offered by $\mathrm{Al}$ and to address the new challenges that it brings". ${ }^{36}$

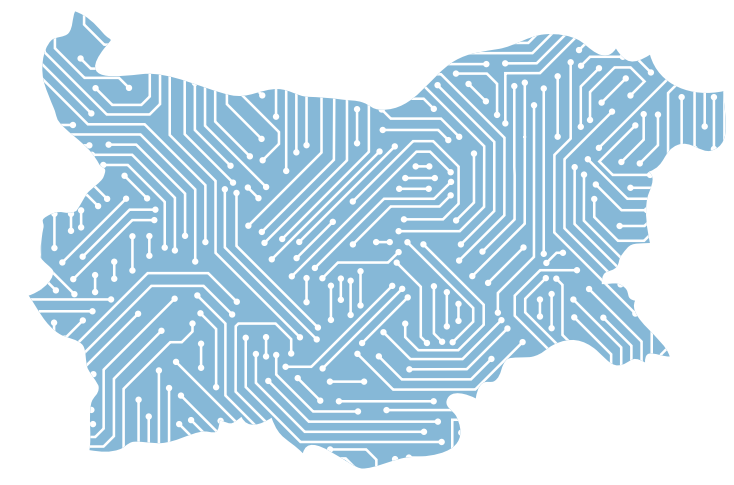

It further suggests three core steps to strengthen the current EU Al ecosystem: 1. boost Europe's technological and industrial capacity as well as Al uptake; 2 . prepare Europe for the socio-economic changes associated with $\mathrm{Al}$; 3 . ensure that Europe has an appropriate ethical and legal framework to deal with Al development and deployment. The Communication proposes several financial and infrastructural mechanisms to increase investment for stagnating areas such as funding into startups and business access to $\mathrm{Al}$ tools. ${ }^{37}$ Other projects of note are the development of regulatory sandboxes, ${ }^{38}$ a commitment to support centres for data sharing and to update access to and preservation of scientific information.

\section{Communication on Al}

Published: 25 April 2018

Author: European Commission

Objective: "The European Union (EU) should have a coordinated approach to make the most of the opportunities offered by $\mathrm{Al}$ and to address the new challenges that it brings. The EU can lead the way in developing and using Al for good and for all, building on its values and its strengths." ${ }^{\prime 3}$

The 'Coordinated Plan on $\mathrm{Al}^{\prime 40}$ is the European Commission's second strategy document.

It's a non-binding proposal building on the previously published 'Communication on $\mathrm{Al}^{\prime}$ and the Declaration of 'Cooperation on Al'. The Plan includes a projected aim of $€ 20 \mathrm{bn}$ in funding by 2020 , with gradual target of $€ 20 \mathrm{bn}$ on a yearly basis thereafter, and lays the foundation for coordination on Al between Member States and other stakeholder groups, with an invitation to cooperate with international stakeholders sharing the same values. This could be considered as the first case of a set of countries attempting a light-touch form of coordination on Al governance. 
The Plan's overarching rationale is that coordination between the Member States can increase the EU's global competitiveness by maximising investment on EU and Member State level, encouraging synergies between ongoing efforts (incl. ethics), exchanging best practices and "collectively define a way forward" 41 , i.e. creating a common goal and vision. The Plan outlines a European approach to Al that is built upon ethical and societal values derived from the Charter of Fundamental Rights. It places an emphasis on what it perceives to be interconnected concepts of a 'trusted $\mathrm{Al}^{\prime}$ and 'human-centric Al'. Key principles identified for the broader goal of achieving Al made in Europe include 'ethics by design' and 'security by design'. It states that "overall, the ambition is for Europe to become the world-leading region for developing and deploying cutting-edge, ethical and secure Al, promoting a human-centric approach in the global context."42 To support this, safety and liability frameworks will be assessed in light of adequate safety and redress mechanisms and, more generally, regulatory frameworks will be assessed for fitness of purpose in regard to Alenabled technologies.

The implementation of the Plan will be supported by the Member States' Group on Digitising European Industry and Artificial Intelligence, steering conversations between

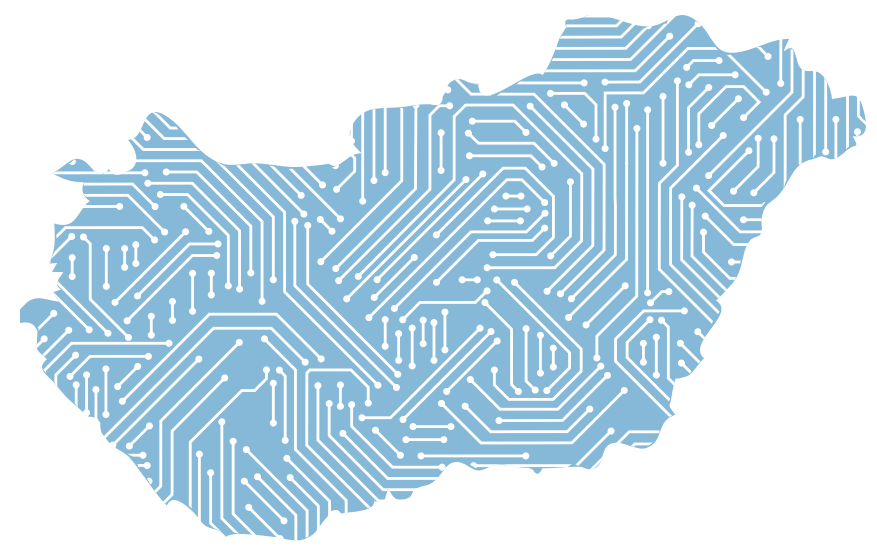

Member States and the European Commission. There will be bi-annual meetings as well as coordination actions across national ministries, industry, academia, civil society and other stakeholders. In addition, academia, industry and the European Commission, with the support of Member States, will work on a common Research and Innovation Agenda for Al (2020). In terms of clear immediate financial goals, Horizon 2020 funding for Al will increase by 70\% between 2018-2020, totalling at $€ 1.5 \mathrm{bn}$. Following, the European Commission proposes an investment of $€ 1 \mathrm{bn}$ per year under the next Multiannual Financial Framework (MFF), drawing on funds from Horizon Europe and the Digital Europe Programme. The Coordinated Plan on $\mathrm{Al}$ also reiterates the 'Communication on $\mathrm{Al}$ "s ambition to increase investment to reach a total of $€ 20 \mathrm{bn}$ until 2020, including public and private funding.

The following areas are identified as being in particular need of coordination: investment, "excellence in and diffusion of $\mathrm{Al}^{\text {", }}$, data availability (pool resources such as data), societal challenges, ethics and regulatory frameworks.

\section{Coordinated Plan on the Development and Use of Artificial Intelligence Made in Europe}

Published: 7th December 2018

Author: European Commission

Objective: "To make these efforts a success [...] Member States and the Union should attempt to align bilateral outreach efforts related to Al between individual Member States and third countries and pool their efforts pushing for a responsible development of Al at the global level. The Union needs to speak with one voice to third countries and the world atlarge on this topic. In synergy with activities of the Member States, the EU should also seek alliances with stakeholders - tech companies, academia and other parties - to engage in a multi-stakeholder alliance at the global level for responsible Al." ${ }^{44}$ 


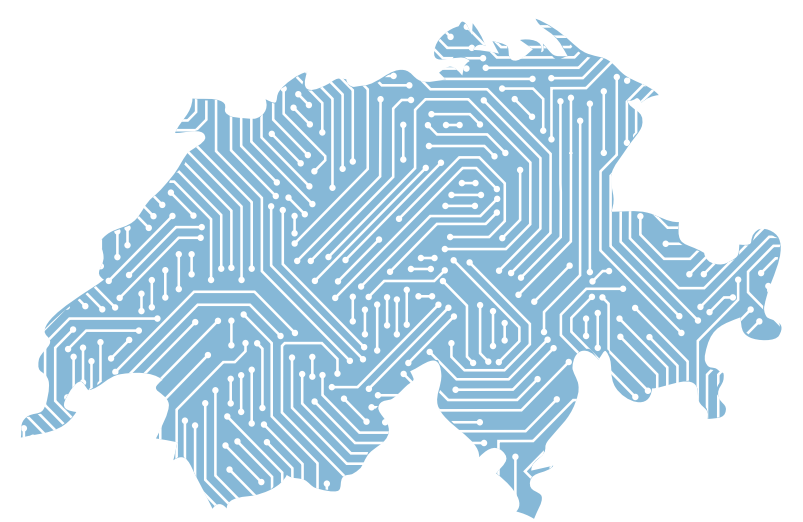

In order to support the development of the Al strategies outlined above, the European Commission established two groups, as described in the Communication on Al: the HighLevel Expert Group on Al (AI HLEG) ${ }^{45}$ and the European Al Alliance. ${ }^{46}$

The High-Level Expert Group on Al contributes to the shaping of the EU's Al strategy, policy and priorities. It advises the European Commission on both near- and longer-term challenges as well as opportunities arising from Al. The AI HLEG further acts as the steering group to the European Al Alliance. Its experts were chosen through an

open call by the European Commission, with the final Group comprising 23 members from industry, 19 from academia, and 10 from civil society. It organises and manages internal and external multi-stakeholder dialogues, resulting in reports and policy suggestions for the European Commission.

The AI HLEG is divided into two working groups (WGs): one on ethics and one on investment and policy. The WG on ethics' remit is to draft $\mathrm{Al}$ ethics guidelines. ${ }^{47}$ This includes an examination of the impact of $\mathrm{Al}$ on the Charter of Fundamental Rights as well as addressing considerations such as nondiscrimination, dignity, privacy and personal data protection, safety and transparency. They recently published their first draft for public consultation through the Al Alliance. The final Guidelines shall be presented to the European Commission by Q1 2019. The WG on investment and policy is tasked with the development of policy and investment recommendations to aid the European Commission in achieving the goals described in the Communication on Al. This includes measures to strengthen the EU's competitiveness, guidance for the Strategic Research Agenda on Al and the establishment of a pan-European network of Al labs.

\section{High-Level Expert Group on AI}

Established: 14th June 2018

Members: 52 members from civil society, academia and industry ${ }^{48}$

Objective: "1. Advise the Commission on next steps addressing Al-related mid to long-term challenges and opportunities [..]; 2. Support the Commission on further engagement and outreach mechanisms [..]; 3. Propose to the Commission Al ethics guidelines [..]." ${ }^{\prime 9}$

The second group, the European Al Alliance, is built around a diverse multi-stakeholder online platform. There, members can contribute to ongoing discussions on $\mathrm{Al}$, feeding into the European Commission's policy-making. They can also directly engage with the AI HLEG, which publishes its draft suggestions on the platform for feedback. The European Al Alliance is open to all members of society. Currently, it is composed of civil society, members of trade unions, companies, not-for-profit institutions and consumer organisations. The Alliance is ambitious in intent; however, the sheer number of members might eventually complicate the platform's management, dilute reasonable voices and ultimately decrease its impact. At the same time the European Al Alliance represents a strong commitment to and leading attempt ${ }^{50}$ at an actual cross-societal and pan-European multistakeholder dialogue. 


\section{European Al Alliance}

Established: 14th June 2018

Members: open to all

Objective: Create a platform for cross-sectorial and open discussions on Al in Europe.

Together, the elements mentioned above form the broad outline of the EU's current strategy for Al. The tonal quality thereof and repeated intention to create 'human-centric', 'trustworthy $\mathrm{Al}^{\prime}$ and 'ethical $\mathrm{Al}^{\prime}$ suggests the EU envisions itself as a leader in these areas.

\section{Section (b): The European Union's Vision}

Section (b) expands on the EU's vision of itself as a leader in 'ethical Al'. When it comes to the creation of a framework for 'ethical Al' the EU may benefit from its "unity in diversity", allowing it to draw on various cultural and historic backgrounds. The EU's path towards Al is one that seems to align with its historic values, including the EU's fundamental values ${ }^{52}$ as defined in the Treaty of Lisbon and its adherence to the European Convention on Human Rights. ${ }^{53}$ Echoing this, the European Commission's Communication on Al states that: "the EU must therefore ensure that $\mathrm{Al}$ is developed and applied in an appropriate framework which promotes innovation and respects Union's values and fundamental rights as well as ethical principles such as accountability and transparency. The EU is also well placed to lead this debate on the global stage. This is how the EU can make a difference - and be the champion of an approach to $\mathrm{Al}$ that benefits people and society as a whole." ${ }^{54}$

Beyond the commitment to a diverse and inclusive dialogue as demonstrated by the $\mathrm{Al}$ Alliance, there are several recent publications, ${ }^{55}$ regulations and projects that strengthen this self-affirming vision of the EU. The most directly relevant publications are the European Group on Ethics in Science and New Technologies' (EGE) statement on 'Artificial Intelligence, Robotics and 'Autonomous Systems", ${ }^{56}$ the AI HLEG's 'Draft Ethics Guidelines for 'Trustworthy Al', and the European Economic and Social Committee's (EESC) 'Opinion on Artificial Intelligence, Artificial intelligence - The consequences of artificial intelligence on the (digital) single market, production, consumption, employment and society ${ }^{.57}$

The EGE's statement calls for the establishment of an overarching framework for Al. To that end, it proposes the development of several ethical principles based on fundamental European values. The principles should act to tackle legal, ethical and governance issues arising from Al development and deployment. Ultimately, their goal should be to ensure that Al is created with "humans in mind". In a forward-thinking manner, the statement also considers that future developments in Al and robotics may need to be accompanied with the introduction of several new rights, such as a "right to meaningful human contact and the right to not be profiled, measured, analysed, coached or nudged".58

To ensure regulatory and ethical foresight, the EGE's statement suggests that a better understanding of future Al-based technologies is needed. It claims that forecasting and measurement in this area could contribute to more accurate policy making by governments and benefit the EU. It is not alone in pointing

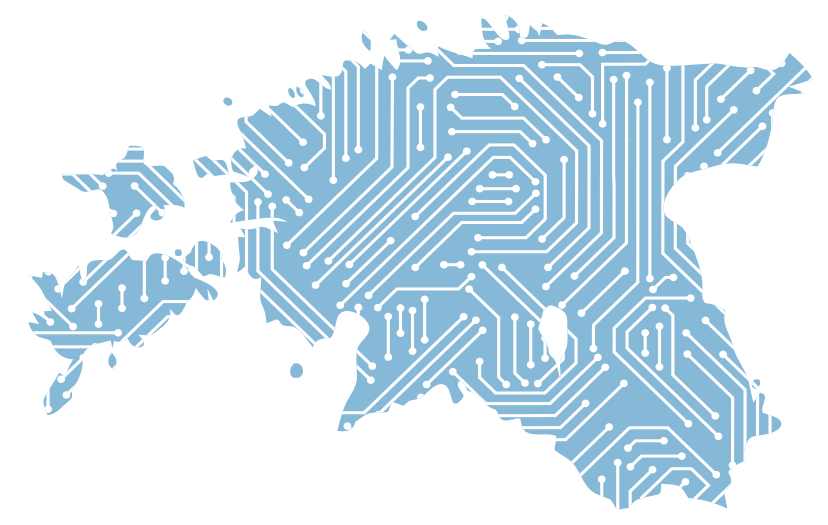


towards the importance of measurement: the Communication on Al mentions the importance of technology monitoring, and national strategy documents such as Germany's Eckpunkte der Bundesregierung für eine Strategie Künstliche Intelligenz propose AI monitoring as a method to produce Al-relevant seals of quality and to set standards. The EU, with a tradition of highquality standard setting, for example with the European Emission Standards, ${ }^{59}$ and certification, for example the Certification Europe (CE) ${ }^{60}$ certifications, could occupy a leading role in Al measurement, standardisation and forecasting. Its attempt to position itself as leader in 'ethical Al' could provide additional credibility for the setting of standards in the areas of safety and human-centric Al development.

The statement also highlights the lack of coordinated, overarching regulations for $\mathrm{Al}$ and Al-based technologies in the EU as a possible blindspot. Potential downsides include reduced competitiveness and 'ethics shopping' (i.e. a situation where companies relocate to or conduct business in countries with lower ethical standards).

\section{Artificial Intelligence, Robotics and 'Autonomous Systems'}

Published: 9th March 2018

Author: European Group on Ethics in Science and New Technologies, European Commission (EGE)

\section{Rapporteur: Jeroen van den Hoven}

Ideas: Among others, the statement suggests ideas for a set of ethical guidelines and democratic prerequisites. They centre around data protection and privacy, sustainability, rule of law and accountability, security, safety, bodily and mental integrity and democracy.

The AI HLEG's 'Draft Ethics Guidelines for 'Trustworthy $\mathrm{Al}^{\prime 61}$ are the clearest indicator of the EU's ambition to become a leader in 'ethical Al'. Although they solely demonstrate the expert group's opinion and are not an official European Commission document, the guidelines nonetheless constitute an insight into the direction that Europe is heading in, namely towards 'human-centric and trustworthy Al'. The draft document contains a variety of chapters ranging from Al's compliance with fundamental rights, technical and non-technical methods to implement the outlined 'trustworthy $\mathrm{Al}^{\prime}$ to an assessment list and case studies for 'trustworthy Al.' 'Trustworthy Al' as used by the AI HLEG is described as made up of two components:"(1) it should respect fundamental rights, applicable regulation and core principles and values, ensuring an "ethical purpose" and (2) it should be technically robust and reliable since, even with good intentions, a lack of technological mastery can cause unintentional harm." ${ }^{62}$ The overall ambition of the guidelines appears to be to incite a discussion of ethical frameworks for $\mathrm{Al}$ "at a global level", one where Europe's approach of using ethics as "inspiration to develop a unique brand of $\mathrm{Al}^{\prime \prime 63}$ is seen as it taking a leadership role and crucial to enable its competitiveness. Furthermore, it is expected to serve as as starting point for a European discussion on "Trustworthy Al made in Europe". ${ }^{64}$ Given that this is only a draft document and will undergo significant changes after the stakeholder consultation is over, it is unclear how the final guidelines will look like.

\section{Draft Ethics Guidelines for Trustworthy Al $^{65}$}

Published: draft published 18th December 2018, undergoing stakeholder consultation

Authors: the AI HLEG's WG on ethics with input from the whole group

Objective: "Given that, on the whole, Al's benefits outweigh its risks, we must ensure to follow the road that maximises the benefits of Al while minimising its risks. To ensure that we stay on the right track, a human-centric approach to Al is needed, forcing us to keep in mind that the development and use of Al should not be seen as a means in itself, but as having the goal to increase human well-being. Trustworthy Al will be our north star, since human beings will only be able to confidently and fully reap the benefits of Al if they can trust the technology."66 
Although the $\mathrm{EESC}^{\prime} \mathrm{s}^{67}$ Opinion on $\mathrm{Al}^{68}$ is the earliest document published from the selection observed, it already hints at narratives recurrent in the above mentioned documents. It recommends the development of a standardisation system that could verify, validate and monitor $\mathrm{Al}$ and $\mathrm{Al}$-based systems and advises that the EU ought to establish a clear policy framework for Al, to ensure global leadership. Both recommendations are salient and strongly dependent on the EU's ability to work as a cohesive whole when it comes to aligning their policies and strategy.

Overall, the Opinion on Al touches on a variety of elements crucial to Al development and deployment, with a heavy focus on ethical, societal and general safety considerations. One recommendation, aligned with many other EU documents and tackled in the Draft Guidelines, is the development of a code for ethics (for the entire creation process from design to development to deployment). ${ }^{69}$ It further backs the call for a ban on lethal autonomous weapons systems and briefly delves into a consideration of the dangers that artificial superintelligence could pose. $^{70}$

In a way, the Opinion can be seen as one of the inflection points for the EU's vision of itself as leader in 'ethical Al'. Throughout the document the rapporteur advocates for a "human-incommand" approach, urges Europe to support and promote the "development of Al applications that benefit society" 71 and even provides tangible next steps to do so.

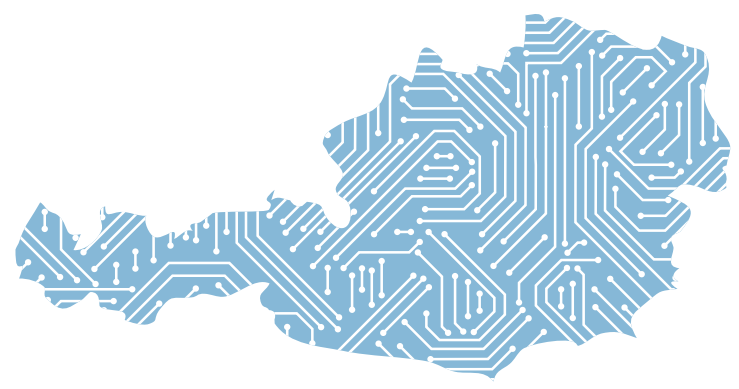

Opinion on Al: Artificial intelligence - The consequences of artificial intelligence on the (digital) single market, production, consumption, employment and society

Published: 31st August 2017

Rapporteur: Catelijne Muller

Objective: The EESC published recommendations concerning the following 11 areas in which AI may create societal challenges: "ethics; safety; privacy; transparency and accountability; work; education and skills; (in)equality and inclusiveness; law and regulations; governance and democracy; warfare; superintelligence." ${ }^{72}$

As demonstrated above, the EU puts a clear emphasis on human-centric and ethical Al, which supports the claim that it sees itself both as a leader in these areas and, related, indicates that it takes this as distinguishing element when compared to other powers aiming for $\mathrm{Al}$ leadership.

This emphasis is further supported by recent EUwide regulation and ongoing projects which the remainder of this section examines. In particular, it will focus on the usage of algorithms and data as well as on citizen empowerment as an avenue towards 'ethical Al'.

When it comes to data protection, the General Data Protection Regulation (GDPR) is a prime example. Discussed for six years, ${ }^{73}$ it took around two years to be finally approved by the European Parliament, replacing the 1995 Data Protection Directive. ${ }^{74}$ While a directive leaves it open to the Member States how to transpose it into national law (as long as the end goal is reached), a regulation is immediately applicable and enforceable. This means that it creates a single approach applicable to ${ }^{75}$ and enforceable by all actors and Member States within the EU. ${ }^{76}$ In this regard, the GDPR contributes to a cohesive regulatory framework for data protection and privacy across the EU. 
In terms of content, the GDPR grants EU citizens greater agency over the way their personal data is being used and reused, and aims to protect it against potential misuse. As part of this, EU citizens have gained a host of new rights: e.g. a right to be forgotten, a right to access and data portability and to privacy by design. The right to be forgotten effectively endows the citizen ${ }^{77}$ with the right to withdraw consent. This means they can demand that previously provided personal information be erased and no longer shared, including with third parties. The right to access grants the citizen with the right to demand a copy of their personal data held by the relevant organisation. ${ }^{78}$ Data portability endows the citizen with the right to move previously provided personal data from one organisation to another. Finally, privacy by design entails that data protection must be part of the initial design of a system.

As a complementary piece of legislation, the EU will soon introduce a new ePrivacy regulation..$^{79,80}$ This would expand and clarify the GDPR's reach as well as broaden its scope to cover areas under online communication.

Despite potential shortcomings, the GDPR is a clear commitment to strengthen data privacy, protect and empower users and by extension lay the foundation for a regulatory approach towards Al that is human-centric. ${ }^{81}$

\section{General Data Protection Regulation}

Came into force: 25th May 2018

Applicable to: all relevant actors within the EU and those who process, monitor or hold data on EU citizens outside of the EU.

Objective: strengthen EU citizens' control over their data and protect them from data and privacy breaches.

In addition to regulatory action, there are also initiatives exploring data usage for the public good such as the DEcentralised Citizen-owned Data Ecosystems (DECODE). ${ }^{82}$ DECODE's aim is to empower citizens to proactively chose the purpose for which their data is used and the method by which it can benefit the public good. At the core of DECODE is a digital wallet, based on distributed ledger technology. The wallet allows each participant to manage if, how and with whom they wish to share their personal data. The idea is not completely unlike the e-Estonia model, where citizens own their information and can access it through a secure online platform..$^{83}$ DECODE currently runs four pilot programs. Each program allows citizens to decide which platforms can access their data. Simultaneously, citizens allow government to use their shared data for public use, for example through the establishment of data commons. ${ }^{84}$ The pilot programs cover areas like healthcare, where citizen's data is shared with the government to inform pertinent policy, and social engagement, where data is used to establish neighbourhood social networks.

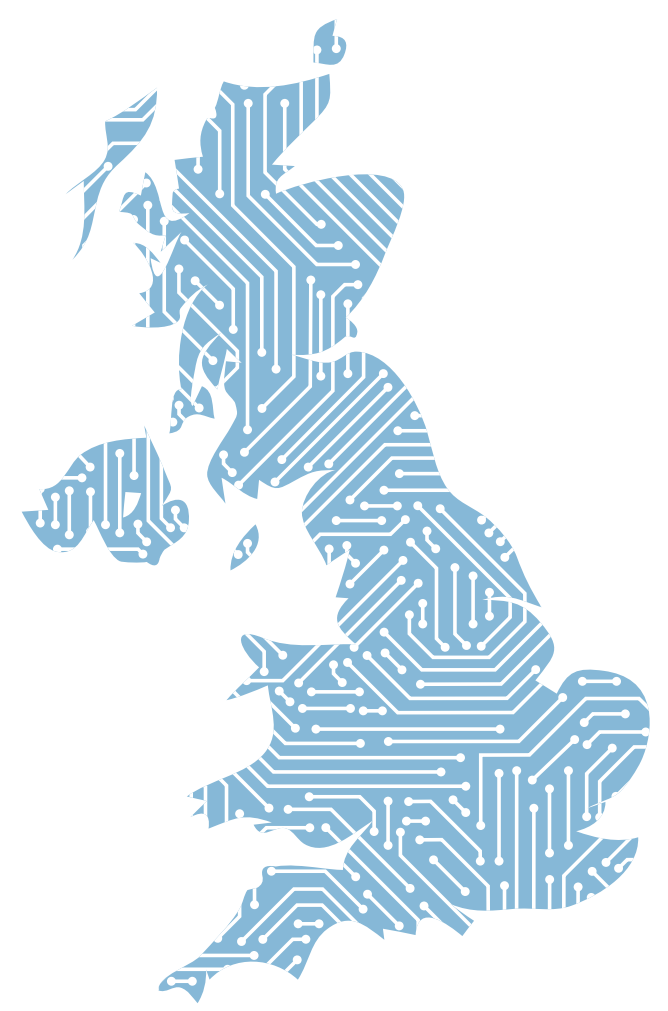




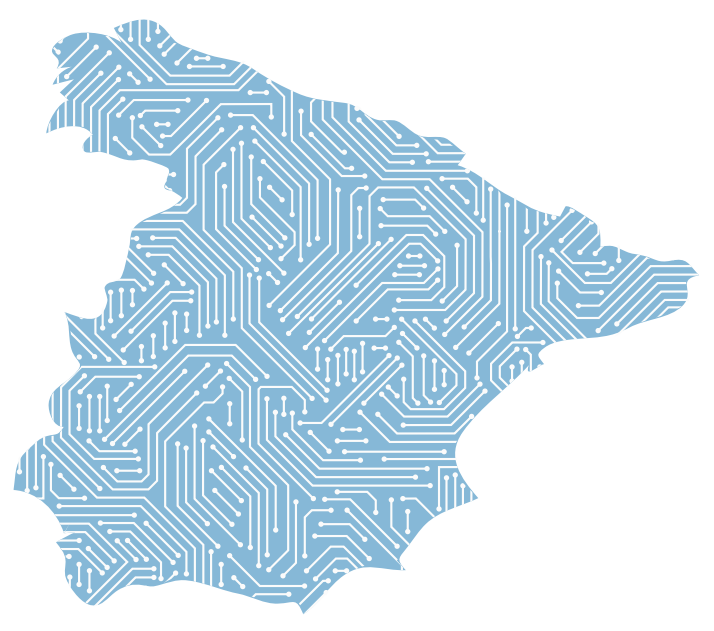

\section{DECODE}

Funded: European Commission with close to $€ 5 m$

Projects: Four Pilot Projects

Members of Pilot Projects: Spain (Barcelona), Netherlands (Amsterdam)

Consortium: 14 partners from across Europe: BCMI Labs AB, City of Amsterdam, CNRS (Centre d'économie de la Sorbonne), Dyne, Eurecat, Institut Municipal d'Informatica de Barcelona (IMI), Nesta, Open University of Catalonia, Politecnico di Torino/

Nexa, Stichting Katholieke Universiteit Nijmegen Privacy \& Identity Lab, Thingful, ThoughtWorks Ltd, University College London, Waag Society.

Another relevant project, currently in its conception phase, is Algo Awareness ${ }^{85}$ which is expected to explore best practices to mitigate risks arising out of algorithmic decision-making. To that end, it will analyse potential risks and conduct a study with citizens, focussing on understanding the impact algorithmic-decision making can have on information flow. It will also investigate how algorithmic decision-making can impact citizens' lives. The analysis and study will result in a reference base outlining benefits and shortcomings associated with algorithmic decision-making. This is expected to help raise public awareness, and contribute to the creation of suitable policy measures. Together with ongoing projects like DECODE and existing regulation such as the GDPR, it can create a landscape where citizens comprehend and steer ongoing debates surrounding data and algorithms.

\section{Algo Awareness}

Established: pilot phase

Objective:"1. contributing to a wider, shared understanding of the role of algorithms, particularly in the context of online platforms, with the intention of raising public awareness and debate of emerging issues; 2 . identifying the types of problems, emerging issues and opportunities raised by the use of algorithms, and establish a scientific evidence-base for these issues and opportunities; and 3. designing and prototyping a policy toolbox including solutions for a selection of problems, including policy options, technical solutions and private sector and civil societydriven actions." 86

\section{Conclusion}

The EU's budding strategy and vision for Al, through the strategic documents and the two main steering groups discussed, unearths a recurrent narrative of 'human-centric' and 'ethical' Al. This naturally leads to a conclusion that the EU envisions itself as a leader in the broad field of 'ethical Al'. This claim is further evidenced by recently introduced regulatory measures (GDPR and ePrivacy Directive), publications (see above) and complementary projects (DECODE and Algo Awareness). Throughout Part 1 it has become evident that the EU's actions align with the vision it has set for itself as a leader in 'ethical Al'. This ambition may contribute to a unique competitive advantage for the $\mathrm{EU}$ in the $\mathrm{Al}$ ecosystem, ${ }^{87}$ if harnessed quickly and appropriately. 


\section{Part 2: The ingredients}

\section{Section (a): Funding and financial support}

The EU's competitiveness is particularly hampered by a lack of VC investment and funding for startups. ${ }^{88}$ According to a recent European Commission press release, ${ }^{89}$ the EU had an investment of about $€ 6.5 \mathrm{bn}$ by venture capitalists in 2016, whereas in the US that number reached $€ 39.4 \mathrm{bn} .{ }^{90}$ While more general funding programmes and national funding vehicles ${ }^{91}$ exist, they are often difficult to locate and limited in size and scope. ${ }^{92}$

The EU cannot retroactively undo past dynamics and oversights, but it is beginning to address these challenges going forward. In addition, the landscape appears to be slowly changing, with VC investment in Europe at a steady rise. ${ }^{93}$

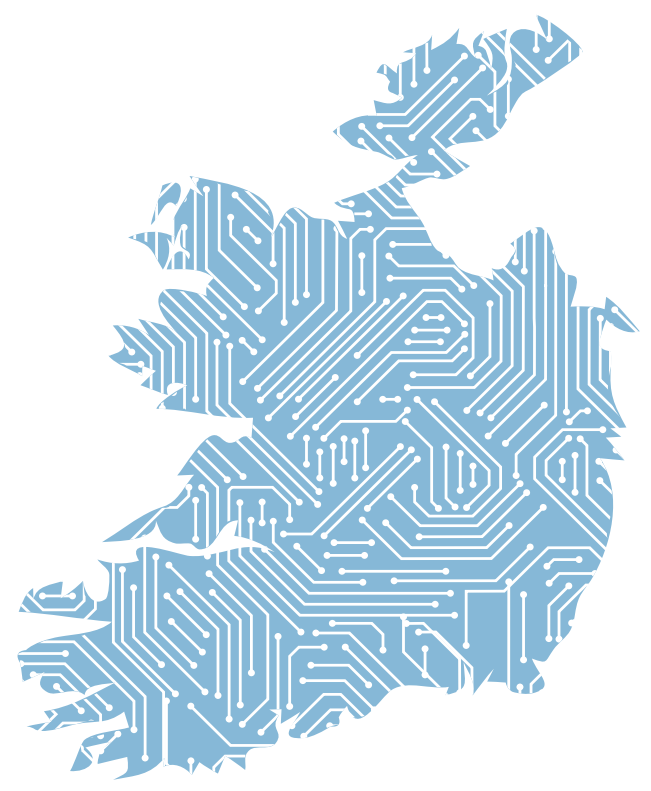

The European Commission in partnership with the European Investment Fund set up a panEuropean VC Funds-of-Funds programme, VentureEU, to tackle the current lack of private investment. VentureEU ${ }^{94}$ benefits from $€ 410 \mathrm{~m}$ which it will distribute to startups and companies that look to scale up within the area of Al. It is furthermore expected to raise an additional $€ 2.1 \mathrm{bn}$ from public and private investment.

\section{VentureEU}

Established: 2018

Lead by: European Commission and European Investment Fund

Budget: $€ 410 \mathrm{~m}$ EU funding, expected to raise additional $€ 2.1 \mathrm{bn}$ of public and private investment

Focus Area: Improve the development and uptake of Al.

The European Fund for Strategic Investment $(E F S I)^{95}$, on the other hand, addresses a more general lack of investment within the EU. It has a budget of $€ 33.5 \mathrm{bn}$ ( $€ 7.5 \mathrm{bn}$ EIB capital) and expects to raise an additional $€ 500$ bn by 2020 . In 2017, the fund reached a total investment of $€ 225.3 \mathrm{bn} .{ }^{96}$ However, these investments are not solely focused on the digital sector (which encompasses Al for the fund's purposes). The investments also support other strategic areas within the EU's economy, including transport, energy, education and research.

The EFSI was launched by the European Investment Bank (EIB) and the European Investment Fund (EIF) ${ }^{97}$ alongside the European Commission and forms part of the Investment 
Plan for Europe: the Juncker Plan..$^{98}$ It is built on the recognition that without investment in innovation, Europe will struggle to remain competitive. The Investment Plan for Europe has three core pillars. It identifies (i) a need to improve the regulatory environment, (ii) a need to support the European investment environment, and (iii) a need for a fund to financially support innovation. The European Investment Advisory Hub ${ }^{99}$ and the European Union Investment Project Portal ${ }^{100}$ support the Juncker Plan.

\section{European Fund for Strategic Investment (EFSI)}

Established: 2015

Lead by: European Investment Bank, European Investment Fund, European Commission

Budget: $€ 26 \mathrm{bn}$ EU budget, $€ 7.5 \mathrm{bn}$ from ElB; aims to unlock additional investment of $€ 500$ bn until 2020

Investment in 2017: €225.3bn

Focus Area: Sectors of "key importance" to Europe e.g. energy, transport, digital, education, research, development and innovation.

The European Commission further commits itself to supporting 'breakthrough' innovation, as well as business ideas, through the European Innovation Council. ${ }^{101}$ To that end, the European Innovation Council has a total of $€ 2$.7bn available (2018-2020) for startups and small companies to help them scale up. The European Innovation Council is not a fund exclusive for Al, but rather for any "highly-risky"102 technology or business idea.

In terms of funding for research and innovation, the European Commission, through Horizon $2020,{ }^{103}$ will spend $€ 1$.5bn on Al between 20182020. This investment is expected to trigger an additional $€ 2.5 \mathrm{bn}$ from existing Public-Private Partnerships, totalling $€ 4 \mathrm{bn}$. ${ }^{104}$ This would constitute a $70 \%$ increase in funding compared

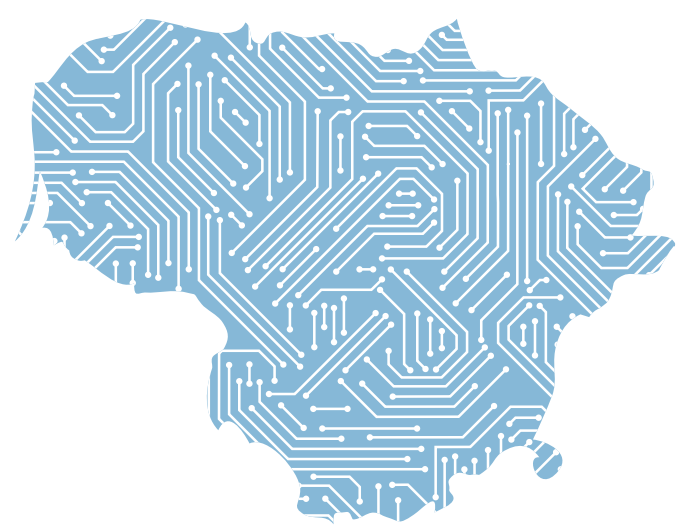

to 2014-2017. The European Commission forecasts that if the private sector and Member States invested alongside this, then total investment into $\mathrm{Al}$ research, development and innovation in the EU could reach $€ 20$ bn by the end of 2020, with a similar amount each subsequent year. ${ }^{105}$

\section{Horizon 2020}

Timeframe: 2014-2020

Lead by: European Commission

Objective: Horizon 2020 is the EU's biggest research and innovation programme with a total funding of around $€ 80 \mathrm{bn}$.

Al specific funding (2018-2020): $€ 2.5 \mathrm{bn}$

Under the next Multiannual Financial Framework (MFF), funding for Al research will be made available by Horizon Europe, the successor to the Horizon 2020 programme, and the Digital Europe programme. ${ }^{106}$ The Digital Europe programme will address areas such as Al, high-performance computing (HPC), digital skills and cybersecurity. The total amount currently proposed to be spent on $\mathrm{Al}$, without matched funding from other sources, is $€ 2.5 \mathrm{bn}$. Other proposed funding includes $€ 2 \mathrm{bn}$ for cybersecurity, $€ 2.7 \mathrm{bn}$ for HPC and $€ 0$.7bn for advanced digital skills development. 


\section{Digital Europe Programme}

Timeframe: 2021-2027

Lead by: European Commission

Objective (Al specific): "(a) build up and strengthen core artificial intelligence capacities in the Union, including data resources and libraries of algorithms in compliance with data protection legislation; (b) make those capacities accessible to all businesses and public administrations; (c) reinforce and network (sic) existing artificial intelligence testing and experimentation facilities in Member States." ${ }^{107}$

Expected Al specific funding: $€ 2.5 \mathrm{bn}$

The previous paragraphs outline several funding instruments as well as expected financial commitments. While these demonstrate acute awareness of the gaps and are designed to address them, it remains to be seen whether they will be sufficient, swift and targeted enough to make a meaningful impact.

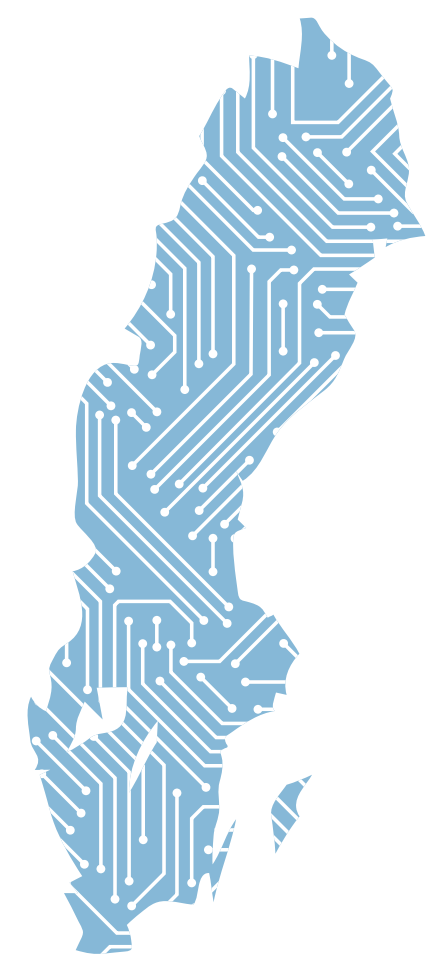

\section{Section (b): Talent creation}

Section (b) focuses on the overlapping areas of brain drain and talent creation. After an introductory note on brain drain in the EU, it focuses on the EU's measures for talent creation.

Brain drain refers to a phenomenon where qualified workers leave a country or institution, often to receive a more competitive salary with better perks elsewhere. With an ongoing global competition for a limited supply of AI talent, ${ }^{108}$ brain drain is not a phenomenon unique to the EU. ${ }^{109}$ Irrespectively, the EU suffers from the migration of European academics to international companies and organisations within Europe as well as to other continents. ${ }^{10,111}$ While the EU is host to many noteworthy academic institutions, salaries are often not competitive enough to keep researchers in academia and teach the next generation. ${ }^{112,113}$ In addition to thereby minimising the potential future talent pool, many European researchers end up working for non-European owned Al companies. ${ }^{114,115,116,117}$ So although they have not directly moved abroad they are now working for a non-European company as opposed to supporting European entreprises. This broadly poses three problems: how to keep talent in the EU (directly or indirectly), how to attract talent to the EU and how to ensure that enough talent is educated to satisfy continuous demand.

Several national strategy documents such as the French Donner un sens à l'intelligence artificielle, ${ }^{118}$ the UK's AI Sector Deal, ${ }^{119}$ or Finland's Finland's Age of Artificial Intelligence ${ }^{120}$ recommend specific steps to tackle these issues. A recurrent suggestion is to increase the number and attraction of academic research careers, through increased funding as well as an increase in the number of $\mathrm{PhD}$ positions. For example, in order to increase the attraction of research careers, Donner un sens à l'intelligence artificielle suggests a doubling of early-career researchers' salaries, general salary top ups, a reduction in administrative formalities and a strong focus on interdisciplinarity research within 
and between institutes. Another suggestion is to increase the number of Al talent moving to the country in question, i.e. facilitating talent attraction. ${ }^{121}$ The Al Sector Deal, for example, proposes a doubling of the number of Tier 1 visas (Exceptional Talent) ${ }^{122,123}$ and a change to the immigration rules for settlement for Tier 1 visa holders. On the other hand, Finland's Age of Artificial Intelligence suggest the creation of an environment that appeals to the families of Al talent, for example, through access to international schools, employment opportunities for spouses, day care centres and an easy immigration process. Similarly, the European Commission notes the importance of "creating an attractive environment"124 for talent attraction and retention.

Beyond Member State initiatives, the EU more broadly acknowledges that it may "risk losing out on the opportunities offered by Al, facing a brain drain and being a consumer of solutions developed elsewhere". ${ }^{125}$ Yet, EU initiatives mainly focus on talent creation with the following paragraphs briefly mapping three areas: training and reskilling, traineeships and national strategies.

The EU introduced measures to address training and reskilling in the digital sector ${ }^{126}$ with the Digital Skills and Jobs Coalition. 127,128 The intention of this Coalition is to endow citizens with the necessary digital skills to navigate society, their current as well as future jobs. It proposes suitable measures for four groups: broad society, labour force (upskilling, reskilling, jobseekers, career advice etc.), ICT professionals, and education (teaching, learning, lifelong learning, educating teachers). A specific milestone of the Digital Skills and Jobs Coalition is to train 1 million young unemployed people for vacancies in the digital sector by 2020 .

Currently, there are $\pm 350,000$ vacancies for digital talent ${ }^{129}$ in Europe with few people able to fill them. To further close this gap, the European Social Fund, ${ }^{130}$ will support Member States with $€ 2$.3bn to use for digital skills development. This will be complemented by the recently launched

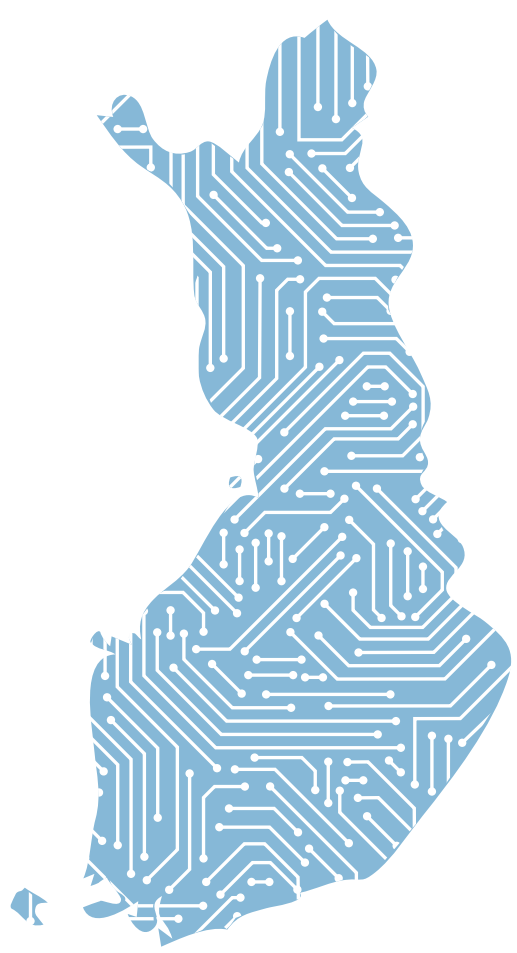

Digital Opportunity Traineeship. ${ }^{131}$ The Digital Opportunity Traineeship is funded by Horizon 2020 and Erasmus+. It offers 6000 students and recent graduates funding for traineeships between 2018-2020.

Finally, as part of the New Skills Agenda for Europe, ${ }^{132}$ the European Commission asked Member States to develop national digital skills strategies by mid-2017, alongside suitable implementation measures. It further issued recommendations to Member States on improving lifelong learning, digital literacy and numeracy. Consistent with the EU's vision of itself as a leader in 'ethical Al', the European Commission also clearly states that training courses and programmes on new technologies such as Al should incorporate ethical considerations. ${ }^{133}$ 


\section{Section (c): Putting the pieces back together}

It is likely that collaboration between the Member States, beyond an alignment in Al strategies, would further strengthen the EU's position in the global Al ecosystem. The following paragraphs introduce suitable existing collaborations and discuss future opportunities in the space.

\section{(i) Large-scale collaboration}

Subsections (i.a), (i.b) and (i.c) explore infrastructural collaborations, joint undertakings in hardware and proposals for pan-European Al laboratories.

\section{(i.a) Active collaboration: infrastructure}

French multinational THALES leads the consortium that won the bid to develop a European Al-on-demand-platform. ${ }^{134}$ The project, Al4EU, ${ }^{135}$ is funded with $€ 20 \mathrm{~m}$ until 2021. Its aim is to create a collaborative Al platform that integrates the entire European Al ecosystem and 'democratises' access to Al.

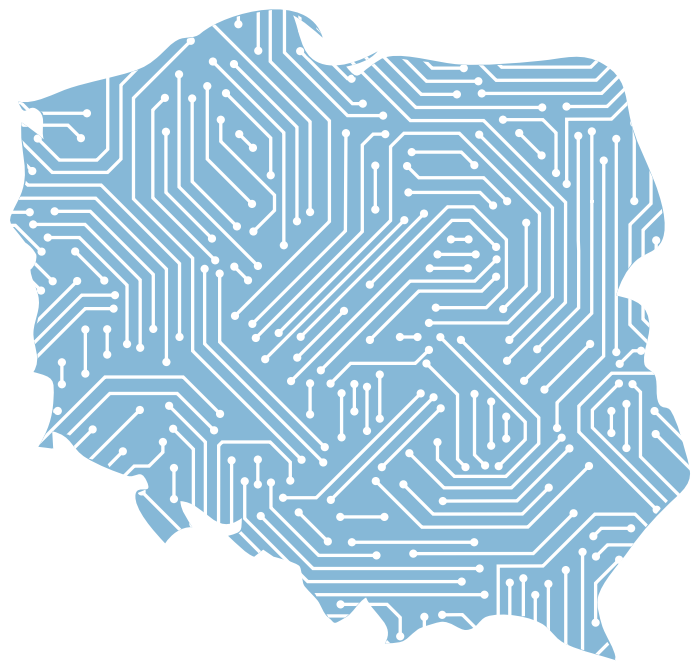

According to the call for proposals, the final Alon-demand platform is expected to compile and provide expertise, algorithms and other tools in an easily accessible format. It is presumed that such a repository will benefit businesses and sectors that do not yet have access to Al or do not have the relevant knowledge to implement Al.

Before that, however, Al4EU will develop eight industry driven Al pilots to explore the value of such a larger Al-on-demand platform as a "technological innovation tool". These pilots will focus on the use of Al for: citizens, robotics, industry applications, healthcare, media, agriculture, loT and cybersecurity. Furthermore, the AI4EU project will establish an Ethics Observatory tasked with monitoring the adherence to human-centric values and create a Foundation managing concerns surrounding sustainability. Lessons learnt from these will feed into the Strategic Research and Innovation Agenda for Europe. The Agenda will further build on ongoing initiatives and strategies such as the robotics Public-Private Partnership, ${ }^{136}$ and the cybersecurity Research Public-Private Partnership. ${ }^{137}$

\section{Al4EU (Al-on-demand platform) ${ }^{138}$}

Budget: $€ 20 \mathrm{~m}$

Consortium: led by Thales, 79 partners in 21 countries are already participating in the project (full list available on the project's website) ${ }^{139}$

Objective:"1. serve as a central point to gather and provide access to Al-related knowledge, algorithms and tools; 2 . support potential users of $\mathrm{Al}$ in order to facilitate the integration of $\mathrm{Al}$ into applications; 3. facilitate the interaction with existing data portals needed for Al algorithms, and resources, such as HPC or cloud computing, and support interoperability." 140 
Another infrastructural collaboration is found in the Digital Innovation Hubs (DIH) ${ }^{141}$ network which is part of the Digital Single Market package ${ }^{142}$ and the Digitise European Industry ${ }^{143}$ effort.

There are currently $\sim 450 \mathrm{DIH}$, each acting as a regional first point-of-contact and provider of a full range of services for SMEs and other businesses. All Hubs are interconnected, together creating a distributed pan-European network of resources. Individual Hubs are made up of organisations such as local universities, incubators/accelerators and industry associations. As a provider, a Hub grants access to sector specific expertise and technology, supporting for example, companies in their testing and experimentation phases. Users of Hubs can also gain access to competence centres (e.g. providing further technological infrastructure), financial and business advice. ${ }^{144}$ While the current network predominantly focuses on robotics, the European Commission's Communication on Al suggested that it could be used to support a "first series of testing and experimentation infrastructures for Al products and services". 145

Bearing this in mind, the European Commission, alongside PwC, Carsa and Innovalia, is currently calling for 30 Digital Innovation Hubs in the field of Al. ${ }^{146}$ These Al-specific Hubs are expected to kickstart a network for collaboration across the EU, as called upon by open letters from the research community such as CLAIRE. In addition, these new Al-specific Hubs are expected to be involved in training programmes, and to "provide evidence for the preparation of relevant European policies". ${ }^{147}$

\section{Digital Innovation Hubs}

Location: 450 DIHs across Europe

Budget: $€ 500$ m over 5 years from the Horizon 2020 framework programme

Objective: "[...] help European Industry, small or large, high-tech or not, to grasp the digital opportunities"148
The following paragraphs introduce different areas of collaboration relevant to Al. In particular, focus is given to SPARC, the Electronic Components and Systems Joint Undertaking and the European High-Performance Computing Joint Undertaking.

\section{(i.b) Active collaboration: Public-Private Partnerships and hardware}

SPARC ${ }^{149}$ is a robotics Public-Private Partnership (PPP) between the European Commission, industry and academia. It is among the largest civilian funded robotics innovation programmes in the world, with $€ 700 \mathrm{~m}$ from the European Commission and $€ 2.1 \mathrm{bn}$ from industry. SPARC primarily aims to strengthen Europe's competitiveness in the field of industrial robotics, where Europe holds a 32\% world market share. ${ }^{150}$ Its broader mission is to redistribute the benefits derived from robotics towards the wider society and reinvest into Europe's economy. To that end, it also promotes the growth of the robotics value chain through public engagement, e.g. the European Robotics week and competitions, e.g. the European Robotics League.

SPARC also consults the European Commission on shifting developments in research, development and innovation through the Strategic Research Agenda (SRA) ${ }^{151}$ and the MultiAnnual Roadmap (MAR). ${ }^{152}$ Both documents provide input into the strategic next steps for the European Commission for the twin focus areas of funding and emerging societal challenges associated with robotics. 


\section{SPARC}

Timeframe: 2014-2020 (established 2012)

Budget: $€ 2.8 \mathrm{bn}$

Location: Brussels, Belgium

Members: 250 including companies, universities and research institutions (including more unusual partners such as hospitals)

Objective: "SPARC aims to make available European robots in factories, in the air, on land, under water, for agriculture, health, rescue services, and in many other applications in Europe which have an economic and societal impact."153

Another, more directly relevant Public-Private Partnership is the Electronic Components and Systems Joint Undertaking (ECSEL). ${ }^{154}$ Electronic components and systems are used in most smart devices, e.g. smartphones, smart energy grid or smart cards and can contribute to the development of a variety of newer technologies, such as neuromorphic chips. The ECSEL PPP, similar to the SPARC PPP within the field of robotics, aims to establish Europe as a global leader in the electronic components and systems industry while supporting the existing ecosystem. ECSEL funds research, development and innovation projects through open calls. In addition, it is in the process of strengthening existing clusters and creating new ones across Europe, ensuring that actors

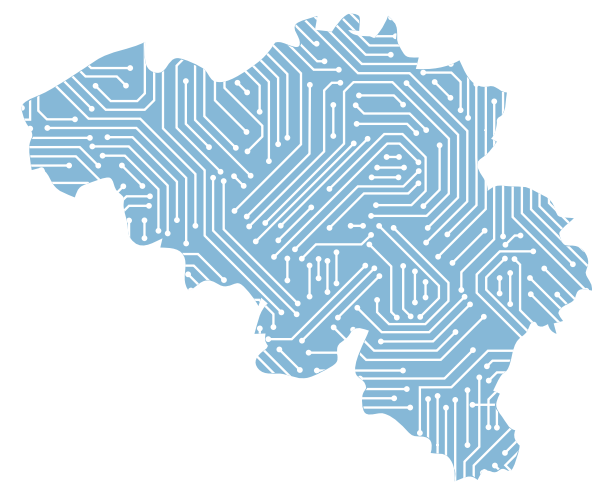

can access the relevant technical infrastructure for the manufacturing and design of electronic components and systems.

\section{Electronic Components and Systems Joint Undertaking}

Established: 2014

Budget: $€ 2.6 \mathrm{bn}$ (comprising $€ 1.4 \mathrm{bn}$ EU and national funding and $€ 1$.2bn industry funding)

\section{Location: Brussels, Belgium}

Objective:"[..] Ensure the availability of electronic components and systems for key markets and for addressing societal challenges, keeping Europe at the forefront of technology development, bridging the gap between research and exploitation, strengthening innovation capabilities and creating economic and employment growth in the Union."155

Members: Austria, Belgium, Bulgaria, Czechia, Germany, Denmark, Estonia, Greece, Spain, Finland, France, Hungary, Ireland, Israel, Italy, Lithuania, Latvia, Luxembourg, Malta, Netherlands, Norway, Poland, Portugal, Romania, Sweden, Slovenia, Slovakia, Turkey, United Kingdom, Switzerland; EU via the European Commission; industry associations: EPoSS, ${ }^{156}$ AENEAS $^{157}$ and ARTEMIS ${ }^{158}$ (e.g. micro- and nano-electronics, smart integrated systems and embedded/cyber-physical systems)

The third relevant initiative is the European High-Performance Computing Joint Undertaking (EuroHPC JU), ${ }^{159}$ established in November 2018. It is a timely move for the EU as highperformance computing has the potential to significantly improve EU competitiveness. One facet of the current lack of supercomputers in the EU, is that researcher often face the need to process their data outside of Europe, possibly under disadvantageous conditions. As a first step towards remedying this situation, the EuroHPC JU will develop a "a clear strategy for innovation procurement of exascale machines 
based on competitive European technologies".160 In addition, it will aid Member States and other European countries in the coordination of their strategies and investments, with the expectation that this will lead to an increase in the development of supercomputers within the European market.

\section{European High-Performance Computing Joint Undertaking}

Established: November 2018

Budget: $€ 486 m$ EU funding (Horizon 2020 and Connecting Europe Facility), total funding of around $€ 1 \mathrm{bn}$, including additional private funding of $>€ 400 \mathrm{~m}^{161}$

Location: Luxembourg, Luxembourg

Members: EU via the European Commission; Austria, Belgium, Bulgaria, Croatia, Czech Republic, Denmark, Estonia, Finland, France, Germany, Greece, Hungary, Ireland, Italy, Latvia, Lithuania, Luxembourg, Netherlands, Norway, Poland, Portugal, Romania, Slovakia, Slovenia and Spain. (Member States and associated countries that signed the declaration and joined since); ${ }^{162}$ European Technology Platform for High Performance Computing (ETP4HPC), Big Data Value (BDVA) and other relevant industry and stakeholder representatives

Objective: "[..] acquiring and providing a world-class pre-exascale ${ }^{163}$ supercomputing infrastructure to Europe's scientific and industrial users, matching their demanding application requirements by 2020 ; developing exascale supercomputers based on competitive EU technology that the Joint Undertaking could acquire around 2022/2023, and that would be ranking among the top three places in the world." 164

\section{(i.c) Proposals for collaboration: pan- European Al laboratories}

Many Al researchers and experts are taking note of the EU's demonstrated strength in large scientific research collaborations, ${ }^{165}$ but also of

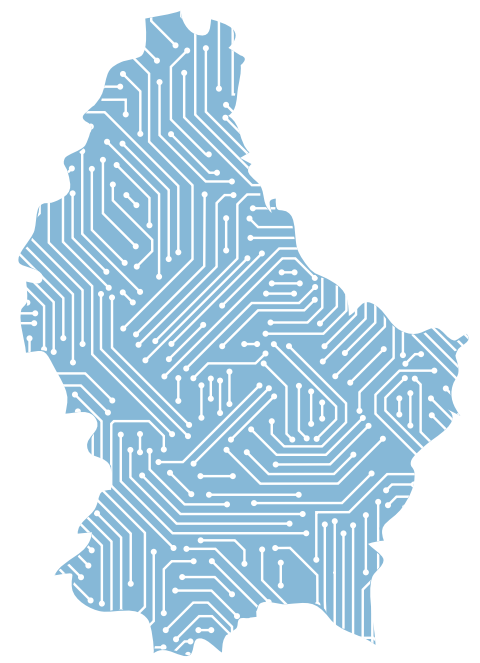

its limited success in transferring this expertise to the field of Al research and development. The latter has been a growing topic of concern in the community, notably expressed through a call to establish a CERN for Al, and two open letters: the European Lab for Learning and Intelligent Systems and the Confederation of Laboratories for Artificial Intelligence Research in Europe. What follows is a brief overview of these three proposals.

As opposed to the latter two, the call for a 'CERN for Al', modelled off the European Organisation for Nuclear Research (CERN), originates from a single advocate, Prof. Gary Marcus. An international collaboration on Al of a scale equal to CERN would ensure that research results are shared globally, ${ }^{166}$ accommodate a high number of interdisciplinary scientists ${ }^{167}$ and benefit from significant funding for ambitious foundational research, he argues.

\section{CERN for Al}

Announcement date: 2017

Proponent: Prof. Gary Marcus

Idea: build a pan-European organisation similar to the European Organization for Nuclear Research (CERN), with equal financial backing and buy-in from a majority of EU Member States

Status: unclear 
In a larger effort, a group of prominent researchers called for the establishment of a European Lab for Learning and Intelligent Systems (ELLIS). ${ }^{168}$ Their open letter argues that while the EU benefits from strong academic research centers, their current distribution across Member States may cause a problematic fragmentation for the EU in the long run. It further notes that a suitable course of action would be to connect capabilities into a crossnational European Al Lab, supported by sufficient funding from participating countries. ${ }^{169}$

In pursuit of this plan, ELLIS recently announced the "formation of its professional association"170 tasked with the management and the creation of the structures needed for the envisaged goal. In addition, ELLIS will push for a pan-European PhD programme and focus on industrial engagement. In terms of research, it aims to hone in on machine learning methods.

\section{European Lab for Learning and Intelligent Systems}

Announcement date: 2018

Proponents: Prof. Zoubin Ghahramani, Chief Scientist at Uber, and Bernard Schölkopf, director at the Max Planck Institute for Intelligent Systems in Tübingen, Germany Idea: "1. we want the best basic research to be performed in Europe, to enable Europe to shape how machine learning and modern Al change the world, and 2. we want to have economic impact and create jobs in Europe, and believe this is achieved by outstanding and free basic research, independent of industry interests." ${ }^{171}$

Status: formally announced "the formation of its professional association that will undertake the organization and building of the intellectual and physical structures of ELLIS"172 in December 2018.

The third and most recent proposal in this same direction is calling for a Confederation of Laboratories for Artificial Intelligence Research in Europe (CLAIRE).

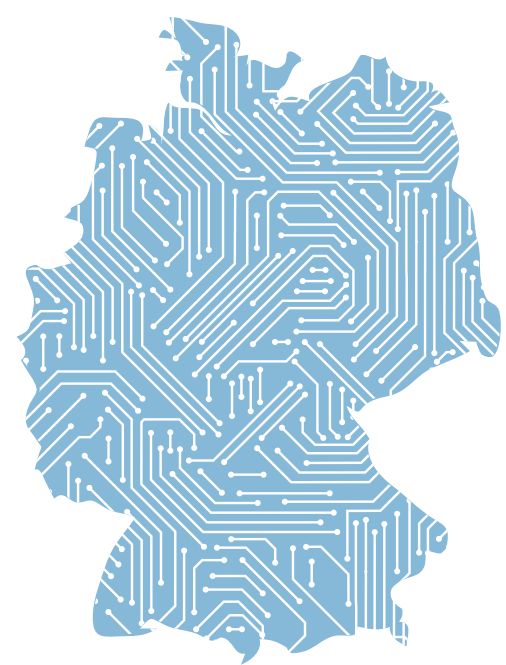

Similar to the rest, it argues that collaboration and coordination within academia and research could contribute to a strengthening of the EU Al ecosystem. To that end, it suggests the establishment of a distributed confederation of Al laboratories with a wide-range of application areas as well as a considerable focus on $\mathrm{Al}$ research for social impact. Unlike others, however, CLAIRE emphasises the importance of the development of trustworthy Al. Since the open letter got published, supporters of ELLIS and CLAIRE agreed to "jointly push for common infrastructure, including compute resources "at Google scale ${ }^{\prime \prime \prime} .173$

The intent to connect Al labs ${ }^{174}$ also features in recent policy publications such as Germany's Eckpunkte der Bundesregierung für eine Strategie Künstliche Intelligenz. ${ }^{75}$

\section{Confederation of Laboratories for Artificial Intelligence Research in Europe}

Announcement date: June 2018

Signatories: over 1900 supporters ${ }^{176}$

Objective: "We call for a vision that aims to (1) have European research and innovation in artificial intelligence be amongst the best in the world, that (2) encompasses all of Al and all of Europe, and that (3) has a strong focus on human-centred $\mathrm{Al}^{\prime \prime 177}$

Status: first symposium in September $2018^{178}$ 


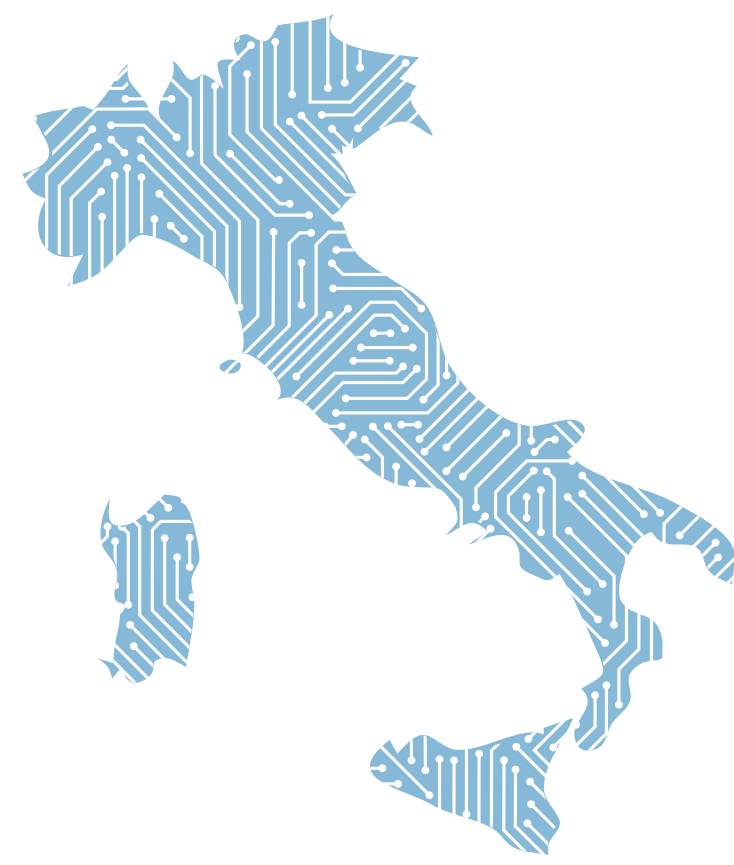

All three calls to action point towards a significant deficit within the EU, as identified by the academic community. This deficit will likely need to be addressed in a timely manner if Europe wishes to remain competitive and strengthen its leadership in Al.

\section{(ii) Granular collaboration}

Whereas the previous section introduced largescale collaborations such as existing frameworks, resources and ongoing proposals for an EU Al laboratory, the following paragraphs focus on smaller scale initiatives between individual groups and actors within Member States.

The Joint European Disruptive Initiative (JEDI) ${ }^{179,180}$ is an upcoming initiative by actors within France and Germany. JEDI hopes to become a 'European idea-factory' that thinks about and funds long-term and high-risk research, an area in which it sees the EU lagging behind. ${ }^{181} \mathrm{JEDI}$ is currently assembling an expert committee which it expects to identify technologies that would enable the European 'deep tech ecosystem' to thrive, if funded by JEDI. As a first step, JEDI is expected to launch 'TechChallenges' under the guidance of business executives, academic researchers and political advisors, ${ }^{182}$ with a focus on Al, cybersecurity, biotechnologies and nanotechnologies. ${ }^{183}$

A conceptually similar idea, that of an EU Agency on Disruptive Innovation, was proposed by President Macron in 2017. 184,185 The importance of such an Agency for Disruptive Innovation is also emphasized in the German Eckpunkte der Bundesregierung für eine Strategie Künstliche Intelligenz ${ }^{186}$ published by the Chancellor's Office in July 2018. In fact, the German 9-Punkte-Plan ${ }^{187}$ issued by the Bundesverband für Künstliche Intelligenz (Federal Association for Artificial Intelligence) directly references JEDI in this regard.

\section{Joint European Disruptive Initiative}

Budget: provisional budget expected $€ 235 \mathrm{~m}$; to expand to $€ 1 \mathrm{bn}$ per year

Established: 2018

Members: lead by André Loesekrug-Pietri, Jean-Paul Palomeros and Didier Schmitt; ${ }^{188}$ conceptually similar ideas have been endorsed by President Macron and Chancellor Merkel as well as in previous meetings hosted by the European Commission ${ }^{189}$

Objective: It hopes to build an agency that identifies and finances moonshot-type projects in Europe.

During the 2018 Al for Humanity Summit ${ }^{190}$ in France, president Macron presented the Paris Artificial Intelligence Research Institute (PRAIRIE) initiative. ${ }^{191}$ With a more national regard than ELLIS and CLAIRE, this initiative looks to strengthen the connection of French Al institutes with other global leaders. The PRAIRIE initiative is currently in its inaugural phase and will be an expansion of a collaborative agreement between several relevant French institutes with leading global Al research centres (e.g. MILA in Montreal, the Max Planck Institute in Tübingen, Germany, and CIIRC in the Czechia). It expects to provide training for researchers at all career stages, to support novel research and knowledge 
transfer as well as to establish close-knit channels between academia and industry. The latter will be supported by a number of industry collaborators forming part of the PRAIRIE's network. Although this initiative outlines both a more nationalistic and global focus than those proposed by ELLIS and CLAIRE, it could still act as a suitable blueprint for a large scale European distributed Al lab. ${ }^{192}$

\section{Paris Artificial Intelligence Research Institute}

Budget: unclear

Established: 2018

Location: Paris, France

Objective: "The partners in PRAIRIE Institute (Paris Artificial Intelligence Research Institute) are pursuing three goals:

1. To make a significant contribution to driving progress in fundamental knowledge in Al freely distributed among the international scientific community;

2. To take part in solving concrete problems with major application-related impact;

3. To contribute to the training in the field of Al.

The five-year objective is to bring together Al scientific and industrial leaders and make the PRAIRIE Institute a world leader in AI."193

Members: French collaborators (academia and industry): CNRS, Inria and PSL University, together with Amazon, Criteo, Facebook, Faurecia, Google, Microsoft, NAVER LABS, Nokia Bell Labs, PSA Group, SUEZ and Valeo; EU collaborators: the Max Planck institute ${ }^{194}$ in Tübingen, the CIIRC ${ }^{195}$ (Czech Institute of Informatics, Robotics and Cybernetics) and the Alan Turing Institute ${ }^{196}$ in London; International collaborators: Center for Data Science at NYU ${ }^{197}$, the artificial intelligence laboratory of UC Berkeley (BAIR), ${ }^{198}$ the Robotics institute ${ }^{199}$ at Carnegie-Mellon University in Pittsburgh, MILA ${ }^{200}$ in Montreal.

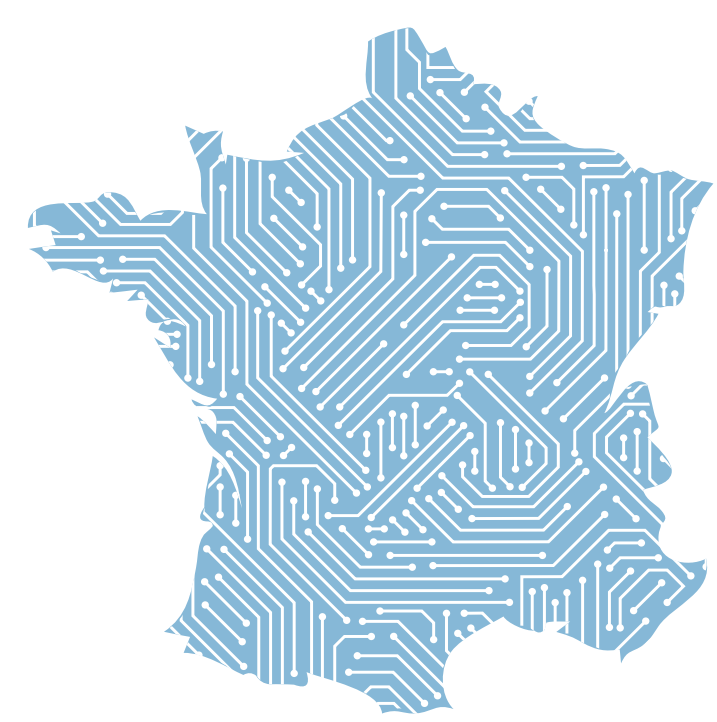

As mentioned previously, the EU benefits from a reputable and thriving academic Al community ${ }^{201}$ and many community members constitute the driving force behind CLAIRE and ELLIS. The European Association for Artificial Intelligence (EurAl), ${ }^{202}$ acts as the representative body of this community. Its mission is to encourage Al research and applications. To that end, it provides awards, grants and organises summer schools for researchers, in addition to sponsoring relevant Masters degrees as well as conferences such as IJCAI-ECAI. It is a valuable player within the EU's Al ecosystem by virtue of connecting and strengthening the existing community and nurturing upcoming talent. ${ }^{203}$ Given EurAl's reach, engagement and activities, it could feasibly play a crucial role in a pan-European Al lab network and support the strengthening of a cooperative research environment within the EU. 


\section{European Association for Artificial Intelligence}

\section{Established: 1982}

Members: Al societies from: Catalonia (Asociación Catalana d'Intelligència Artificial), ${ }^{204}$ Ukraine (Ассоциация Создателей и Пользователей Интеллектуальных Систем), ${ }^{205}$ Spain (Asociación Española para la Inteligencia Artificial), ${ }^{206}$ France (Association Française pour I'Intelligence Artificielle), ${ }^{207}$ Ireland (Artificial Intelligence Association of Ireland), ${ }_{1}^{208}$ Italy (Associazione Italiana per I'Intelligenza Artificiale), ${ }^{209}$ United Kingdom (Society for the Study of Artificial Intelligence and Simulation of Behaviour), ${ }^{210}$ United Kingdom (Specialist Group on Artificial Intelligence), ${ }^{211}$ Portugal (Associação Portuguesa para a Inteligência Artificial), ${ }^{212}$ Romania (Asociaţia Română pentru Inteligenţă Artificială), ${ }^{213}$ Bulgaria (Bulgarian Artificial Intelligence Association), ${ }^{214}$ Benelux (Benelux Association for Artificial Intelligence), ${ }_{1}^{215}$ Czechia (Česká společnost pro kybernetiku a informatiku), ${ }_{1} 16$ Denmark (Danish Artificial Intelligence Society), ${ }_{2} 17$ Greece (Hellenic Artificial Intelligence Society), ${ }^{218}$ Finland (Suomen Tekoälyseura), ${ }^{219}$ Germany (Fachbereich Künstliche Intelligenz der Gesellschaft für Informatik), 220 Israel (Israeli Association for Artificial Intelligence), ${ }_{1}^{221}$ Latvia (Latvijas Automatikas Nacionala Organizacija), 222 Lithuania (Lietuvos Kompiuterininku Sajunga), ${ }^{223}$ Norway (Norwegian Artificial Intelligence Society), ${ }^{224}$ Hungary (Neumann János Számítógéptudományi Társaság), ${ }^{225}$ Austria (Österreichische Gesellschaft für Artificial Intelligence), ${ }^{226}$ Poland (Polish Artificial Intelligence Society), ${ }^{227}$ Russia (Российская ассоциация искусственного интеллекта), ${ }^{228}$ Sweden (Swedish Artificial Intelligence Society), ${ }^{229}$ Switzerland (Swiss Group for Artificial Intelligence and Cognitive Science), ${ }^{230}$ Slovenia (Slovenian Artificial Intelligence Society), ${ }^{231}$ Slovack Republic (Slovenská spoločnost' pre kybernetiku a informatiku pri SAV), ${ }^{232}$

Objective: "The objectives of the Association, which is non-profit making, are: to promote the science and technology of artificial intelligence in Europe; to promote the establishment of a European computer network; to encourage the teaching of artificial intelligence; to publish a European journal of information on artificial intelligence; to sponsor a biennial conference organized by one or more of the member societies. The Association includes a subcommittee responsible, in particular, for coordinating and promoting activities inside the European Community." ${ }^{233}$

\section{Conclusion}

The above sections focus on some of the building blocks needed to support an EU Al strategy: (a) funding, (b) talent creation and (c) collaboration.

Section (a) outlines funding mechanisms such as VentureEU and the European Fund for Strategic Investment as well as other sources of funding for research, development and innovation (e.g. Horizon 2020, the European Innovation Council pilot and the Digital Europe Programme). It concludes that the $\mathrm{EU}$ is addressing past shortcomings in a variety of areas such as VC funding, however, it is unclear whether new initiatives will be successful or swift enough to achieve a change in direction. Section (b) addresses brain drain and talent creation. While the EU supports talent creation through education, upskilling and reskilling (e.g. the Digital Opportunity Traineeship and the Digital Skills and Jobs Coalition), it appears to pay less attention to talent retainment and attraction.

Section (c) focuses on collaboration between a variety of large (e.g. EU institutions, Member States) and small actors (e.g. groups within Member States). Subsection (i) outlines existing pan-European frameworks and resources (e.g. DIH, SPARC, ECSEL, EuroHPC JU). It then proceeds to examine three ongoing proposals for a panEuropean Al lab which could feasibly build upon and use these existing resources: CERN for Al, ELLIS and CLAIRE. Subsection (ii) introduces more granular initiatives such as JEDI and PRAIRIE. Although there are several promising collaborations within the EU, only further reviews will clarify whether these are necessary and sufficient for the EU to strengthen its leadership in Al. 


\section{Summary}

This report explores some of the necessary and existing elements for Al leadership in the EU. In doing so, it provides an introductory overview of the EU's Al ecosystem by surveying relevant policy and strategy documents, regulations, projects and initiatives.

The elements explored are strategy and vision, funding, talent creation and collaboration.

Overall, the EU may have an opportunity to distinguish itself from other nations with its strategy and vision, if the current focus on 'ethical $\mathrm{Al}^{\prime}$ is expanded, clarified and implemented. Depending on how this effort turns out, it could contribute to the EU's longer-term competitive advantage. New initiatives and pilot programmes address historic gaps in VC funding, alongside billions dedicated towards AI R\&D during the remaining Horizon 2020 framework programme and the upcoming Digital Europe Programme at EU-level alone. This tackles some prior blind spots and creates a suitable stepping stone for the EU to go forwards. Unfortunately, actual impact of many funding initiatives will only be clear several years into their term. While brain drain is of concern to the EU, there are few successful counteractions momentarily identified and implemented. Instead, the EU is undertaking an array of initiatives to support talent creation at all levels: education, reskilling and upskilling. Finally, the EU benefits from various large scale and smaller projects of collaborative nature in areas such as hardware, research and infrastructure that could strengthen the EU as a singular actor. 


\section{Annex}

Ongoing models for large-scale collaboration

In the broader field of science and technology, two prominent contenders for established pan-European collaborations are the European Organization for Nuclear Research (CERN) and the Human-Brain Project (HBP). CERN is "Europe's first joint venture"234 and the HumanBrain Project is a European flagship project, which means that it is one of the EU's "visionary, science-driven, large-scale research initiatives addressing grand Scientific and Technological (S\&T) challenges".235 CERN and the Human-Brain Project receive significant funding from the EU and additional financial backing is provided by each participating Member State. CERN and the $\mathrm{HBP}$ are significant institutions for Europe, acting as signposts for the EU's capability to undertake large-scale collaborative research and could act as inspiration for what European Al projects or labs of similar scope may look like.

CERN's main research aim is to study particle physics. It is most commonly associated with the discovery of the Higgs boson particle. Based on a single site, CERN currently has 22 involved countries, alongside several Associated Countries and organisations listed as observers.

\section{European Organization for Nuclear Research}

Established: 1954

Location: Geneva, Switzerland

Members (countries): Belgium, Denmark, France, Germany, Greece, Italy, Netherlands, Norway, Sweden, Switzerland, United Kingdom, Austria, Spain, Portugal, Finland, Poland, Czechia, Hungary, Bulgaria, Israel, Romania, Slovak Republic

Associate Members States in pre-stage to membership: Cyprus, Serbia, Slovenia; Associated Member States: India, Lithuania, Pakistan, Turkey, Ukraine ${ }^{236}$

Observer Status: UNESCO, European Commission, the Joint Institute for Nuclear Research (JINR), Japan, Russia, United States

Staff: 2,$633 ; 12,236$ users (as of $31 / 12 / 2017$ )

Budget: CHF 1,148,2m (as of 13/03/18)

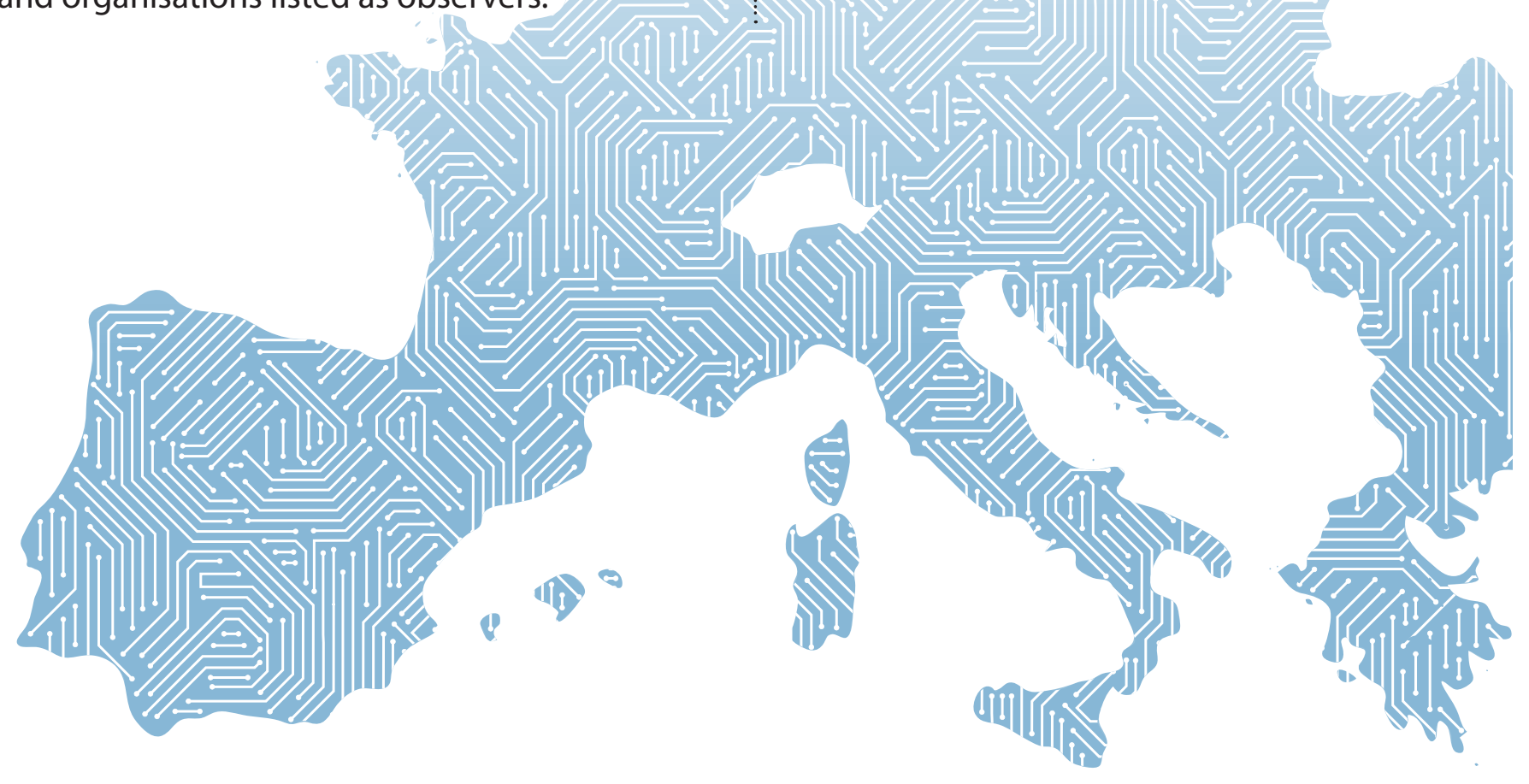




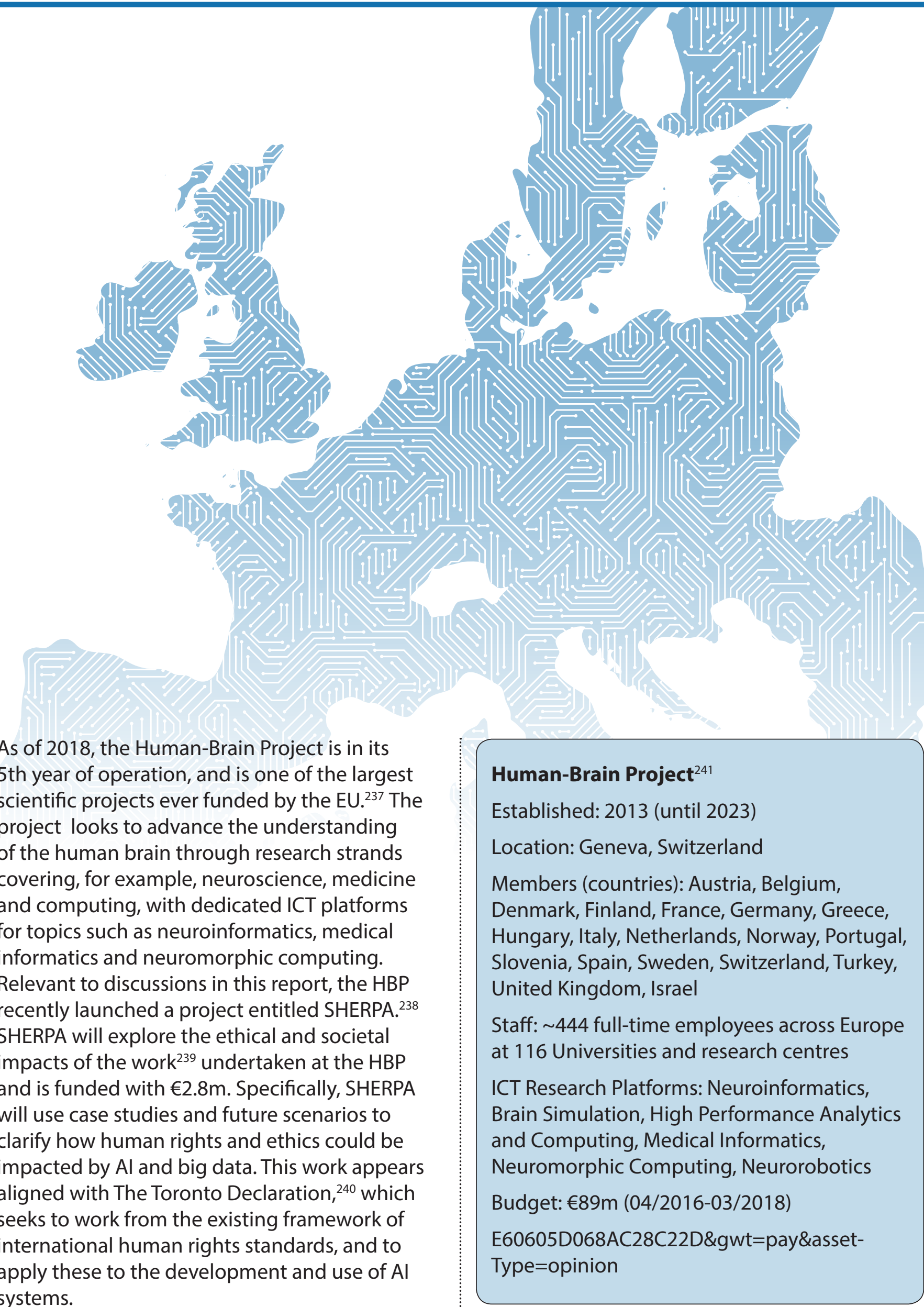




\section{Footnotes}

1. This report focuses on the EU rather than Europe, the continent. Respectively, the adjective 'European' refers to the political and economic union.

2. This report does not consider the implications of Brexit.

3. e.g. https://www.technologyreview.com/s/608112/ who-is-winning-the-ai-race/; https://www.wired. co.uk/article/why-china-will-win-the-globalbattle-for-ai-dominance, https://www.forbes.com/ sites/forbestechcouncil/2017/12/05/these-sevencountries-are-in-a-race-to-rule-the-world-withai/\#cc695f4c245f;

4. https://www.politico.eu/article/opinion-europes-aidelusion/

5. https://www.merics.org/en/blog/europes-ai-strategyno-match-chinas-drive-global-dominance

6. https://www.politico.eu/article/merkel-artificialintelligence-warns-brain-drain-to-foreign-techcompanies/

7. https://www.nrc.nl/nieuws/2018/08/27/nederlandkampt-met-ai-braindrain-a1614393

8. See: https://ec.europa.eu/digital-single-market/en/ news/european-artificial-intelligence-landscape

9. http://data.consilium.europa.eu/doc/document/ST8507-2018-INIT/en/pdf

10. https://www.entrepreneur.com/article/313692

11. The total number expected, taking into account existing Public-Private Partnerships, is €4bn.

12. This number excludes any matched or industry funding as well as funding on Member State level.

13. http://europa.eu/rapid/press-release_IP-18-2763_ en.htm

14. https://www.recode.net/2016/7/18/12213472/ softbank-buying-arm-chip-design

15. https://www.bloomberg.com/news/ articles/2017-03-08/midea-eyes-top-spot-for-kuka-inchina-s-booming-robot-market

16. https://techcrunch.com/2016/06/20/twitter-is-buyingmagic-pony-technology-which-uses-neural-networksto-improve-images/
17. https://www.politico.eu/article/opinion-europes-aidelusion/

18. https://www.merics.org/en/blog/europes-ai-strategyno-match-chinas-drive-global-dominance

19. https://www.politico.eu/article/merkel-artificialintelligence-warns-brain-drain-to-foreign-techcompanies/

20. https://www.nrc.nl/nieuws/2018/08/27/nederlandkampt-met-ai-braindrain-a1614393

21. See: https://ec.europa.eu/digital-single-market/en/ news/european-artificial-intelligence-landscape.

22. For the EU's purposes this includes, but is not limited to, the development, application and deployment of Al.

23. Full title: "Artificial intelligence - The consequences of artificial intelligence on the (digital) single market, production, consumption, employment and society"

24. https://www.bmbf.de/files/180718\%20Eckpunkte_KIStrategie\%20final\%20Layout.pdf; no official English translation. The title translates to Cornerstones of the Federal Government for an Artificial Intelligence Strategy.

25. http://julkaisut.valtioneuvosto.fi/bitstream/ handle/10024/160391/TEMrap_47_2017_ verkkojulkaisu.pdf? sequence $=1$ \&isAllowed $=y$

26. https://www.aiforhumanity.fr/pdfs/9782111457089 Rapport_Villani_accessible.pdf

27. It is not within the scope of this report to examine the whole landscape relevant to any form of Al leadership.

28. http://europa.eu/rapid/press-release_IP-18-6689_ en.htm

29. https://ec.europa.eu/digital-single-market/en/ news/eu-member-states-sign-cooperate-artificialintelligence

30. A declaration is a legally non-binding document. It is an official statement outlining the intent of its signatories.

31. See: https://ec.europa.eu/digital-single-market/en/ news/eu-member-states-sign-cooperate-artificialintelligence. 
32. https:/ec.europa.eu/digital-single-market/en/ news/eu-member-states-sign-cooperate-artificialintelligence

33. It is unclear what is meant by "harm" in this specific case.

34. See: https://ec.europa.eu/digital-single-market/en/ news/eu-member-states-sign-cooperate-artificialintelligence.

35. https://ec.europa.eu/digital-single-market/en/news/ communication-artificial-intelligence-europe

36. https://ec.europa.eu/digital-single-market/en/news/ communication-artificial-intelligence-europe

37. Part 2 of this report concerns itself in more depth with the available and proposed financial instruments.

38. Regulatory sandboxes are also mentioned in a recent memorandum of understanding between UAE and India. See: https://gulfnews.com/news/uae/ government/uae-and-india-sign-agreement-onartificial-intelligence-1.22580.

39. https://ec.europa.eu/digital-single-market/en/news/ communication-artificial-intelligence-europe

40. https://ec.europa.eu/digital-single-market/en/news/ coordinated-plan-artificial-intelligence

41. https://ec.europa.eu/digital-single-market/en/news/ coordinated-plan-artificial-intelligence

42. https://ec.europa.eu/digital-single-market/en/news/ coordinated-plan-artificial-intelligence

43. https://ec.europa.eu/digital-single-market/en/news/ coordinated-plan-artificial-intelligence

44. https://ec.europa.eu/digital-single-market/en/news/ coordinated-plan-artificial-intelligence

45. https://ec.europa.eu/digital-single-market/en/news/ call-high-level-expert-group-artificial-intelligence

46. https://ec.europa.eu/digital-single-market/en/ european-ai-alliance

47. First draft published 18th December 2019.

48. Full list: https://ec.europa.eu/digital-single-market/en/ high-level-expert-group-artificial-intelligence.

49. https://ec.europa.eu/digital-single-market/en/news/ call-high-level-expert-group-artificial-intelligence

50. The Future Society's Global Civic Debate is a similar project with a slightly different scope. In addition, there are also national initiatives inspired by the European Al Alliance such as ALLAI Nederland.

51. The motto of the EU: https://europa.eu/europeanunion/about-eu/symbols/motto_en.

52. http://europarlamentti.info/en/values-and-objectives/ values/
53. https://www.echr.coe.int/Documents/Convention ENG.pdf

54. https://ec.europa.eu/digital-single-market/en/news/ communication-artificial-intelligence-europe

55. Other publications are e.g. Mady Delvaux's 2017 report with recommendations to the Commission on Civil Law Rules on Robotics (European Parliament: 2015/2103 (INL)) and the European Data Protection Supervisor's Ethics Advisory Group 2018 opinion Towards a new Digital Ethics (Opinion 4/2015).

56. https://ec.europa.eu/research/ege/pdf/ege_ai_ statement_2018.pdf

57. https://www.eesc.europa.eu/en/our-work/opinionsinformation-reports/opinions/artificial-intelligence

58. https://ec.europa.eu/research/ege/pdf/ege_ai_ statement_2018.pdf

59. https://ec.europa.eu/growth/sectors/automotive/ environment-protection/emissions_en

60. https://www.certificationeurope.com

61. https://ec.europa.eu/digital-single-market/en/news/ draft-ethics-guidelines-trustworthy-ai

62. https://ec.europa.eu/digital-single-market/en/news/ draft-ethics-guidelines-trustworthy-ai

63. https://ec.europa.eu/digital-single-market/en/news/ draft-ethics-guidelines-trustworthy-ai

64. https://ec.europa.eu/digital-single-market/en/news/ draft-ethics-guidelines-trustworthy-ai

65. https://ec.europa.eu/digital-single-market/en/news/ draft-ethics-guidelines-trustworthy-ai

66. https://ec.europa.eu/digital-single-market/en/news/ draft-ethics-guidelines-trustworthy-ai

67. The EESC is the representative body of the European civil society.

68. Full title:"

69. This is now in development under the remit of the Al HLEG.

70. https://en.wikipedia.org/wiki/Superintelligence

71. https://www.eesc.europa.eu/en/our-work/opinionsinformation-reports/opinions/artificial-intelligence

72. https://www.eesc.europa.eu/en/our-work/opinionsinformation-reports/opinions/artificial-intelligence

73. https://iapp.org/resources/article/a-brief-history-ofthe-general-data-protection-regulation/

74. 95/46/EC

75. Non-compliance incurs a tiered fine of up to $4 \%$ of annual global turnover or $€ 20 \mathrm{~m}$. 
76. The GDPR also applies to actors located outside of the EU, provided they monitor, process or hold data of EU citizens or offer services and goods to them.

77. In this case, the term 'citizen' always refers to the data subject.

78. This includes a right to be informed whether the data was processed and for what purposes.

79. https://iapp.org/media/pdf/resource_center/ ePR_2018-04-13.pdf

80. The ePrivacy regulation represents an update to the current ePrivacy directive.

81. However, several commentators worry that the GDPR may hamper innovation in the area of $\mathrm{Al}$ in Europe and negatively affect the ecosystem.

82. https://decodeproject.eu/what-decode

83. https://www.newyorker.com/magazine/2017/12/18/ estonia-the-digital-republic

84. This broadly means that the data is collectively owned and managed by the citizens and government.

85. http://www.algoaware.eu

86. http://www.algoaware.eu

87. https://tem.fi/en/article/-/asset_publisher/ministerilintila-yritykset-mukaan-tekoalyn-eettiseenhyodyntamiseen

88. See: https://venturebeat.com/2018/10/12/vcinvestment-in-european-startups-plunged-21in-q3-2018/; http://europa.eu/rapid/press-release_IP18-2763_en.htm; https://www.startupgrind.com/ blog/the-3-key-differences-between-europeanvs-us-startups/; https://ec.europa.eu/info/law/ law-making-process/evaluating-and-improvingexisting-laws/refit-making-eu-law-simpler-andless-costly/refit-platform_en; http://www.eib.org/ efsi/what-is-efsi/index.htm; https://www.bcg.com/ publications/2015/alliances-joint-ventures-growthstate-of-european-venture-capital.aspx; https:// startupeuropepartnership.eu/how-eu-programmescan-help-innovators-and-startups/; https://www. europeanceo.com/business-and-management/eulaunches-venture-capital-programme-to-boost-startup-growth/.

89. http://europa.eu/rapid/press-release_IP-18-2763_ en.htm

90. In 2016, the population of the United States of America was around 323m (https://www.census. gov/popclock/), whereas the population of the EU was around 512m (https://ec.europa.eu/eurostat/ documents/2995521/8102195/3-10072017-AP-EN. pdf/a61 ce1 ca-1 efd-41df-86a2-bb495daabdab).

91. See e.g.: https://catapult.org.uk
92. See: https://www.politico.eu/article/germanyfalling-behind-china-on-tech-innovation-artificialintelligence-angela-merkel-knows-it/;https://www. politico.eu/article/merkel-artificial-intelligence-warnsbrain-drain-to-foreign-tech-companies/; https:// www.ft.com/content/57ba6236-f766-11e6-bd4e68d53499ed71.

93. https://blog.dealroom.co/annual-european-venturecapital-report-full-37-page-pdf-report/

94. http://europa.eu/rapid/press-release_IP-18-2763_ en.htm

95. http://www.eib.org/en/efsi/

96. https://eur-lex.europa.eu/legal-content/EN/ TXT/?uri=COM:2017:479:FIN

97. http://www.eif.org

98. https://ec.europa.eu/commission/priorities/jobsgrowth-and-investment/investment-plan-europejuncker-plan_en

99. http://eiah.eib.org

100. https://ec.europa.eu/eipp/desktop/en/index.html

101. See https://ec.europa.eu/research/eic/index.cfm. The European Innovation Council is currently in its pilot phase.

102. It remains unclear how "highly risky" is defined in this context.

103. https://ec.europa.eu/programmes/horizon2020/

104. https://ec.europa.eu/digital-single-market/en/news/ communication-artificial-intelligence-europe

105. This is a speculative and non-committal number proposed in the European Commission's Communication on $\mathrm{Al}$ and the Coordinated Plan on Al.

106. http://ec.europa.eu/info/law/better-regulation/ initiatives/com-2018-434_en

107. $\operatorname{COM}(2018) 434 / 977620$

108. http://www.jfgagne.ai/talent/

109. https://www.expatinvestor.com/articles/ opportunities-for-ai-machine-learning

110. https://www.politico.eu/article/merkel-artificialintelligence-warns-brain-drain-to-foreign-techcompanies/

111. https://ec.europa.eu/digital-single-market/en/news/ european-artificial-intelligence-landscape

112. https://www.artificialintelligence-news. com/2017/11/01/universities-losing-best-ai-scientists/

113. https://www.nrc.nl/nieuws/2018/08/27/nederlandkampt-met-ai-braindrain-a 1614393

114. https://www.telegraph.co.uk/technology/2018/09/02/ britain-faces-artificial-intelligence-brain-drain/ 
115. https://www.nytimes.com/2018/07/03/technology/ cambridge-artificial-intelligence.html

116. https://www.politico.eu/article/merkel-artificialintelligence-warns-brain-drain-to-foreign-techcompanies/

117. In addition, many promising, formerly European, companies have been acquired by international competitors. Examples include: DeepMind (Google), Acorn RISC Machine (acquired by Softbank), Swiftkey (Microsoft), KUKA (Midea), Magic Pony Technology (Twitter), and VocallQ (Apple).

118. English title: For a Meaningful Artificial Intelligence; See http://www.ladocumentationfrancaise.fr/ rapports-publics/184000159/index.shtml

119. https://www.gov.uk/government/publications/ artificial-intelligence-sector-deal/ai-sector-deal

120. http://julkaisut.valtioneuvosto.fi/bitstream/ handle/10024/160391/TEMrap_47_2017_ verkkojulkaisu.pdf

121. This approach does not take into account whether talent ends up at nationally owned companies.

122. https://www.gov.uk/browse/visas-immigration/workvisas

123. http://www.ukvisas.com/tier-1-exceptional-talentvisa-digital-technology/

124. https://ec.europa.eu/digital-single-market/en/news/ communication-artificial-intelligence-europe

125. https://ec.europa.eu/digital-single-market/en/news/ communication-artificial-intelligence-europe

126. This means areas including and related to Al but not exclusively focused on $\mathrm{Al}$.

127. https://ec.europa.eu/digital-single-market/en/digitalskills-jobs-coalition

128. For a more general exploration of training needs across other areas is offered in the Blueprint for Sectorial Cooperation on Skills see: http://ec.europa. $\mathrm{eu} /$ social/main.jsp?catld=1415\&langld=en.

129. https://www.cognizant.com/whitepapers/21-jobs-ofthe-future-a-guide-to-getting-and-staying-employedover-the-next-10-years-codex3049.pdf

130. http://ec.europa.eu/esf/home.jsp

131. https://ec.europa.eu/digital-single-market/en/digitalopportunity-traineeships-boosting-digital-skills-job

132. https://eur-lex.europa.eu/legal-content/EN/ TXT/?uri=CELEX\%3A52016DC0381; http://europa.eu/ rapid/press-release_IP-18-102_en.htm

133. https://ec.europa.eu/digital-single-market/en/news/ communication-artificial-intelligence-europe
134. http://ec.europa.eu/research/participants/portal/ desktop/en/opportunities/h2020/topics/ict-26-20182020.html

135. https://ai4eu.org

136. https://ec.europa.eu/digital-single-market/en/ robotics-public-private-partnership-horizon-2020

137. https://ecs-org.eu/cppp

138. https://cordis.europa.eu/programme/rcn/703011_ en.html

139. https://ai4eu.org

140. http://ec.europa.eu/research/participants/portal/ desktop/en/opportunities/h2020/topics/ict-26-20182020.html

141. http://s3platform.jrc.ec.europa.eu/digital-innovationhubs

142. https://ec.europa.eu/commission/priorities/digitalsingle-market_en

143. https://ec.europa.eu/digital-single-market/en/pillarsdigitising-european-industry-initiative

144. The Digital Hub Denmark initiative, as described in Denmark as a digital frontrunner, suggests a comparable but smaller scale concept, to "support business access to specialist expertise and opportunities for cooperation on the development of new business models". See: https://em.dk/english/ publications/2017/denmark-as-digital-frontrunner.

145. https://ec.europa.eu/digital-single-market/en/news/ communication-artificial-intelligence-europe

146. https://ec.europa.eu/digital-single-market/en/news/ call-digital-innovation-hubs-artificial-intelligence

147. https://ec.europa.eu/digital-single-market/en/news/ call-digital-innovation-hubs-artificial-intelligence

148. http://s3platform.jrc.ec.europa.eu/digital-innovationhubs

149. https://www.eu-robotics.net/sparc/about/index.html

150. https://eu-robotics.net/sparc/about/robotics-ineurope/index.html

151. https://www.eu-robotics.net/sparc/upload/topic_ groups/SRA2020_SPARC.pdf

152. https://www.eu-robotics.net/sparc/upload/topic groups/H2020_Robotics_Multi-Annual_Roadmap_ ICT-2017B.pdf

153. https://www.eu-robotics.net/sparc/about/index.html

154. https://www.ecsel.eu

155. https://www.ecsel.eu

156. https://www.smart-systems-integration.org/public

157. https://aeneas-office.org 
158. https://artemis-ia.eu

159. https://ec.europa.eu/digital-single-market/en/ eurohpc-joint-undertaking

160. https://ec.europa.eu/digital-single-market/en/ eurohpc-joint-undertaking

161. https://ec.europa.eu/digital-single-market/en/ connecting-europe-facility

162. https://ec.europa.eu/digital-single-market/en/news/ european-declaration-high-performance-computing; https://ec.europa.eu/digital-single-market/en/ eurohpc-joint-undertaking

163. According to Wikipedia exascale computing refers to "refers to computing systems capable of at least one exaFLOPS, or a billion billion (i.e. a quintillion) calculations per second."

164. https://ec.europa.eu/digital-single-market/en/ eurohpc-joint-undertaking

165. As introduced in the annex.

166. https:/www.nytimes.com/2017/07/29/opinion/ sunday/artificial-intelligence-is-stuck-hereshow-to-move-it-forward.html?smid=twnytopinion\&smtyp $=$ cur\&_r $=0$ \&mtrref $=\mathrm{t}$.

167. https://ethicsofalgorithms.org/2018/05/22/opinionpiece-why-we-need-a-cern-for-ai/

168. https://ellis-open-letter.eu

169. https://www.theguardian.com/science/2018/apr/23/ scientists-plan-huge-european-ai-hub-to-competewith-us

170. https://ellis.eu/ellis_announcement.pdf

171. https://ellis-open-letter.eu

172. https://ellis-open-letter.eu/ellis_announcement.pdf

173. https://claire-ai.org/updates/

174. This is initially expected to be between France and Germany.

175. https://www.bmbf.de/files/180718\%20Eckpunkte_KIStrategie\%20final\%20Layout.pdf

176. https://claire-ai.org/all-supporters/

177. https://claire-ai.org/wp-content/uploads/2018/06/ CLAIRE-Vision-Document-1.pdf

178. https://claire-ai.org/symposium/

179. https://www.euractiv.com/section/economy-jobs/ news/return-of-the-jedi-european-disruptivetechnology-initiative-ready-to-launch/

180. https://www.politico.eu/pro/europe-channels-its-jediin-effort-to-become-innovation-leader/

181. It is inspired by the American Defense Advanced Research Projects Agency (DARPA).
182. This paragraph is influenced by edits and comments received from JEDI's F. Haenel.

183. https://www.euractiv.com/section/economy-jobs/ news/return-of-the-jedi-european-disruptivetechnology-initiative-ready-to-launch/

184. https://drive.google.com/file/d/OB_eo0GD8CMEZWpXVktRbmdOcTg/view?ts=59cadcc8

185. https://sciencebusiness.net/news/macron-wants-seteu-agency-disruptive-innovation

186. https://www.bmbf.de/files/180718\%20Eckpunkte_KIStrategie\%20final\%20Layout.pdf

187. English tite: 9-Point-Plan. See: http://ki-verband.de/9punkte-plan.

188. https://www.euractiv.com/section/economy-jobs/ news/return-of-the-jedi-european-disruptivetechnology-initiative-ready-to-launch/

189. https://ec.europa.eu/digital-single-market/en/news/ european-artificial-intelligence-landscape

190. https://www.aiforhumanity.fr/en/

191. https://www.inria.fr/en/news/news-from-inria/launchof-the-prairie-institute

192. Germany is proposing a similar initiative. In its Eckpunkte der Bundesregierung für eine Strategie Künstliche Intelligenz, it mentions the concept of connecting research labs, with an initial focus on France and Germany.

193. https://www.inria.fr/en/news/news-from-inria/launchof-the-prairie-institute

194. https://www.is.mpg.de

195. https://www.ciirc.cvut.cz

196. https://www.turing.ac.uk

197. https://cds.nyu.edu

198. http://bair.berkeley.edu

199. https://www.ri.cmu.edu

200. https://mila.quebec/en/

201. https://ec.europa.eu/digital-single-market/en/news/ european-artificial-intelligence-landscape

202. https://eurai.org

203. EurAl's President Prof. Barry O'Sullivan is a member of the European High-Level Expert Group on Al and the chair of their working group on policy and investment.

204. http://www.acia.cat

205. http://www.aduis.com.ua/

206. http://www.aepia.org/

207. http://www.afia.asso.fr/ 
208. http://4c110.ucc.ie/aiai/

209. http://www.aixia.it/

210. http://www.aisb.org.uk/

211. http://www.bcs-sgai.org/

212. http://www.appia.pt/

213. http://www.aria-romania.org/

214. https://eurai.org/node/5

215. http://www.bnvki.org/

216. http://www.cski.cz/

217. http://www.daimi.au.dk/\%7Ebmayoh/dais.html

218. http://www.eetn.gr/

219. http://www.stes.fi/

220. http://fbki.kuenstliche-intelligenz.de/

221. http://www.iaai.org.il/

222. https://eurai.org/node/15

223. http://www.liks.lt/

224. https://eurai.org/node/18

225. http://www.njszt.hu/

226. http://www.oegai.at/

227. http://www.pssi.agh.edu.pl/en:start

228. http://raai.org/president/

229. http://www.sais.se/

230. http://sgaico.s-i.ch/

231. http://slais.ijs.si/

232. http://www.sski.sk/

233. https://eurai.org/documentation/charter

234. https://home.cern/about

235. http://ec.europa.eu/programmes/horizon2020/en/ h2020-section/fet-flagships

236. Full list: https://home.cern/about/member-states.

237. The second one is Graphene. A flagship project on Quantum Computing is under way: https://ec.europa. eu/commission/commissioners/2014-2019/ansip/ blog/race-quantum-taking-computing-new-leveleurope_en. The HBP and Graphene are funded under Horizon 2020.

238. https://www.humanbrainproject.eu/en/follow-hbp/ news/hbps-ethics-director-to-lead-europe-widecomputer-ethics-project/

239. http://www.project-sherpa.eu

240. https://www.accessnow.org/the-toronto-declarationprotecting-the-rights-to-equality-and-nondiscrimination-in-machine-learning-systems/
241. https://sos-ch-dk-2.exo.io/public-website-production/ filer_public/54/d5/54d586bd-4f0f-4761-8d92-

78e13cb09efa/hbp_facts_and_figures.pdf 
